\title{
Comparative anatomy and phylogeny of the Forcipulatacea (Echinodermata: Asteroidea): insights from ossicle morphology
}

\author{
MARINE FAU ${ }^{1, *, \oplus}$ and LOÏC VILLIER ${ }^{2}$ \\ ${ }^{1}$ Department of Geosciences, University of Fribourg, Chemin du Musée 6, 1700 Fribourg, Switzerland \\ ${ }^{2}$ Centre de Recherche en Paléontologie - Paris, UMR 7207 CNRS - MNHN - Sorbonne Université, 4 \\ place Jussieu, 75005 Paris, France
}

\begin{abstract}
A new phylogenetic analysis of the superorder Forcipulatacea is presented. Forcipulatacea is one of the three major groups of sea stars (Asteroidea: Echinodermata), composed of 400 extant species. The sampled taxa are thought to represent the morphological diversity of the group. Twenty-nine forcipulate taxa were sampled belonging to Asteriidae, Stichasteridae, Heliasteridae, Pedicellasteridae, Zoroasteridae and Brisingida. Specimens were dissected with bleach. Detailed description of the skeleton and the anatomy of the ossicles were investigated using scanning electron microscopy. Comparative anatomy allowed the scoring of 115 phylogenetically informative characters. The consensus tree resulting from the analysis recovers Asteriidae, Stichasteridae, Zoroasteridae and Brisingida as monophyletic. All types of morphological features contribute to tree resolution and may be appropriate for taxon diagnosis. The synapomorphies supporting different clades are described and discussed. Brisingida and Zoroasteridae are the best-supported clades. The potentially challenging position of Brisingida in the tree may be explained by homoplastic changes, but also by the presence of numerous non-applicable characters.
\end{abstract}

ADDITIONAL KEYWORDS: Asteriidae - Asteroidea - Brisingida - Forcipulatacea -ossicles - phylogeny sea stars - starfish - Stichasteridae - Zoroasteridae.

\section{INTRODUCTION}

With approximately 1900 extant species, Asteroidea (sea stars or starfish) is one of the most diverse of the five extant clades of echinoderms (Mah \& Blake, 2012). They occur worldwide in cold to tropical waters from the tidal zone to the abyss and exhibit a large variety of shapes, sizes and ecology.

The first attempts at a higher classification of Asteroidea were made in the late $19^{\text {th }}$ century (Viguier, 1878; Perrier, 1884; Sladen, 1889; Perrier, 1894). Viguier (1878) used the anatomy of the mouth frame to define his groups. Perrier (1884) divided Asteroidea into four orders (Forcipulatida, Spinulosida, Valvatida and Paxillosida) according to characteristics of the pedicellariae. Sladen (1889) based his classification on the development of the marginal ossicles (Phanerozonia versus Cryptozonia).

*Corresponding author. E-mail: marine.fau@unifr.ch
In the early $20^{\text {th }}$ century, Fisher $(1911,1928,1930)$ made changes to the classifications established by Sladen (1889) and Perrier (1884). Spencer \& Wright's (1966) classification was the first to reconstruct a comprehensive phylogeny that included both extinct and extant taxa. However, many of their groupings were supported by the overall similarities of body shapes and many extinct taxa were interpreted inaccurately as members of extant families.

Since the 1980s, phylogenetic analyses have shown synapomorphies for a clade that includes all postPalaeozoic Asteroidea, also called Neoasteroidea (Blake, 1987; Gale, 1987). Since these studies, many have supported this hypothesis, both with morphological and molecular evidence, but the internal topology of Neoasteroidea is still highly debated (e.g. Wada et al., 1996; Janies \& Mooi, 1998; Janies, 2001; Blake \& Elliott, 2003; Blake \& Hagdorn, 2003; Gale, 2011; Janies et al., 2011; Mah \& Foltz, 2011a, b; Mah \& Blake, 2012; Blake \& Mah, 2014; Feuda \& Smith, 2015; Linchangco et al., 2017). 
In addition to Valvatacea and Spinulosacea, Forcipulatacea is currently considered to form one of the three primary clades of Neoasteroidea (Mah \& Foltz, 2011a, b; Mah \& Blake, 2012). The group consists of approximately 400 extant species that occur worldwide and are divided into two orders, Forcipulatida and Brisingida (Mah \& Blake, 2012). Although Forcipulatacea is morphologically diverse, its monophyly is widely accepted (e.g. Blake, 1987; Gale, 1987; Mah, 2000; Foltz et al., 2007; Gale, 2011; Mah \& Foltz, 2011a; Mah et al., 2015; Linchangco et al., 2017). With about half of the described species, the Asteriidae represents the greatest diversity of Forcipulatacea, followed by the Brisingida, which represents a quarter of forcipulatacean diversity (Mah \& Blake, 2012). Historically, Forcipulatacea was either split into several families, such as Pycnopodiidae, Labidiasteridae, Neomorphasteridae and Stichasteridae, or lumped into more inclusive taxa, such as Asteriidae, Zoroasteridae and Brisingida (e.g. Clark \& Downey, 1992; Mah \& Foltz, 2011a). However, recent molecular-based phylogenetic analyses have provided new evidence that many of these groupings are unnatural (Mah, 2000; Foltz et al., 2007; Mah \& Foltz, 2011a; Mah et al., 2015). Four main clades seemed well-supported by morphological and molecular evidence: Zoroasteridae, Stichasteridae, Brisingida and Asteriidae (Mah \& Foltz, 2011a; Mah et al., 2015), but molecular data has suggested that Pedicellasteridae is polyphyletic, Labidiasteridae is a synonym of Heliasteridae and Neomorphasteridae a synonym of Stichasteridae (Mah \& Foltz, 2011a). Despite the new insights provided by molecular data, the phylogeny of the Forcipulatacea remains unclear, the internal topology of different clades is still unstable and morphological synapomorphies often remain ambiguous (Fig. 1; e.g. Mah, 2000; Janies et al., 2011; Mah \& Foltz, 2011a; Mah et al., 2015; Linchangco et al., 2017).

All echinoderms have a mesodermal skeleton made of calcite ossicles that articulate via mutable connective tissues and muscles. Echinoderm skeletons have been extensively studied since the late $19^{\text {th }}$ century; first, mainly for taxonomic purposes (e.g. Cuénot, 1887; Turner \& Dearborn, 1972), but more recently for phylogenetic purposes (e.g. Blake \& Hagdorn, 2003; Villier et al., 2004; Kroh \& Smith, 2010; Gale, 2011; Thuy \& Stöhr, 2016). Phylogenetic characters have been developed and implemented for echinoids and ophiuroids (Kroh \& Smith, 2010; Thuy \& Stöhr, 2016). Despite these promising results, asteroid ossicles have only been studied in detail by a few authors (Cuénot, 1887; Blake, 1972, 1973; Turner \& Dearborn, 1972; Gale, 2011; Fau \& Villier, 2018) and were seldom used in phylogenetic analysis, mainly in palaeontological studies (Blake, 1987; Gale, 1987; Mah, 2000; Blake \& Elliott, 2003; Villier et al., 2004; Mah et al., 2010; Gale, 2011). The most recent phylogenetic hypotheses for Forcipulatacea were based on molecular data (Mah \& Foltz, 2011a; Mah et al., 2015) and have provided new insights into the history of this group.

Here, we provide a detailed description of the ossicle anatomy of 29 forcipulatacean species. The comparative anatomy results are used for phylogenetic purposes. The derived phylogenetic tree is discussed in regard to molecular-based trees. The taxonomic groups composing Forcipulatacea are redefined with morphological synapomorphies.

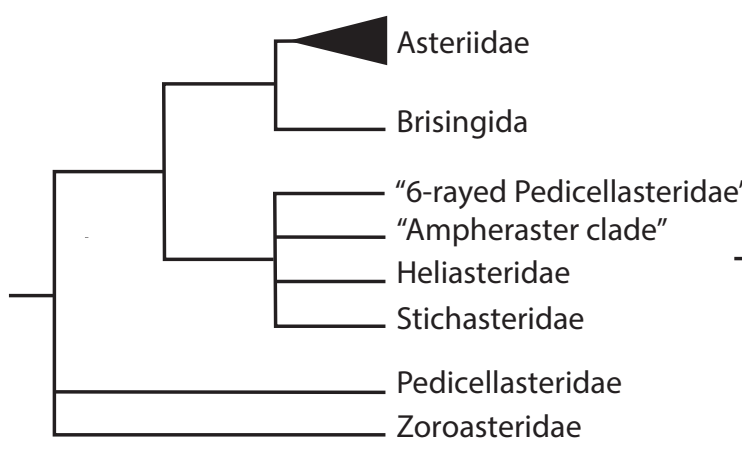

Mah \& Foltz, 2011a

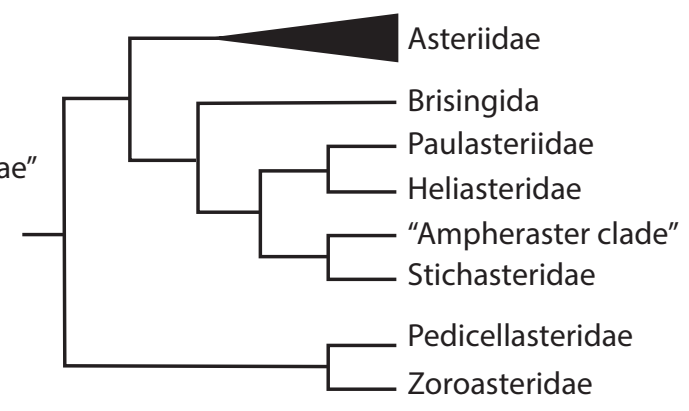

Mah et al., 2015

Figure 1. Summary of the most recent phylogenetic hypothesis of the Forcipulatacea derived from molecular data by Mah \& Foltz (2011a) and Mah et al. (2015). Both studies used the same genes data set (mitochondrial 16S rDNA, 12S rDNA and nuclear early stage histone H3) and were performed using maximum likelihood. One species was added in Mah et al., 2015. The reconstructed tree of Mah \& Foltz (2011a) is the strict consensus of the two phylogenetic trees published. The clades 'six-rayed Pedicellasteridae' and Paulasteriidae refer to the same taxa, two species of Paulasteriidae were described in Mah et al. (2015) and were, therefore, not yet named in Mah \& Foltz (2011). The family Pedicellasteridae is polyphyletic in both analyses, because it includes the clade Pedicellasteridae and the 'Ampheraster clade'. 


\section{MATERIAL AND METHODS}

\section{TAXON SAMPLING}

In order to effectively sample diversity across Forcipulatacea, species were selected based on the phylogenetic classification of Mah \& Foltz (2011a), which is the most comprehensive and the most recent phylogenetic hypothesis for this clade. We sampled 29 forcipulatacean taxa (Table 1; for a list of all the specimens observed see Supporting Information, File S1) from nine of the eleven clades proposed by Mah \& Foltz (2011a) (i.e. 'Pan-Tropical Asteriidae', 'Antarctic Asteriidae', 'Boreal Asteriidae', 'Sclerasterias clade' within Asteriidae, Brisingida, Heliasteridae, Stichasteridae, Pedicellasteridae and Zoroasteridae). Taxa were selected to represent the morphological diversity of the Forcipulatacea as accurately as possible, but constraints in the availability of specimens for dissection partially limited sampling. Half of the taxa dissected are Asteriidae (Table 1), because Asteriidae represents half of the species diversity of Forcipulatacea (Mah \& Blake, 2012). The clade 'Ampheraster' and the family Paulasteriidae (Mah et al., 2015), which was designated as a 'six-rayed Pedicellasterid clade' in Mah \& Foltz (2011a), could not be sampled because of the scarcity of these taxa in collections.

The identity of the sister-group of the Forcipulatacea is still under debate (e.g. Blake, 1987; Gale, 1987; Blake \& Hagdorn, 2003; Gale, 2011; Janies et al., 2011; Mah \& Foltz, 2011a, b; Blake \& Mah, 2014; Mah et al., 2015; Linchangco et al., 2017). As it is the goal of this study to resolve the internal phylogeny of the Forcipulatacea, not to find their position within the Asteroidea, the outgroup was primarily selected based on ossicle morphology, in that taxa were preferred as outgroups that could be scored for most characters. Along this line, taxa with derived morphology, such as Velatida, were dismissed because of difficulties in inferring homologies with Forcipulatacea, even though some molecular phylogenies considered them to be the sister-group of Forcipulatacea (Janies et al., 2011; Feuda \& Smith, 2015; Linchangco et al., 2017). Two valvatacean taxa were, therefore, selected as outgroups instead: the paxillosidan Plutonaster bifrons (Wyville Thomson, 1873) and the valvatidan Dactylosaster cylindricus (Lamarck, 1816).

Specimens were graciously provided by the Muséum National d'Histoire Naturelle (MNHN), Paris, France, and the Yale Peabody Museum of Natural History (YPM), New Haven, Connecticut, USA. Four specimens belong to the palaeontology collection of the University of Fribourg (UniFR), Fribourg, Switzerland.

\section{DISSECTIONS AND TERMINOLOGY}

The dissections followed protocols as described by Fau \& Villier (2018). Specimens were immersed in a dilute solution of sodium hypochlorite (bleach), rinsed, dried and the isolated ossicles were then mounted on scanning electron microscope (SEM) stubs. Samples were SEM-imaged using a Hitachi TM3000 (Centre de Recherche en Paléontologie - Paris, France) and a FEI XL30 Sirion FEG (Université de Fribourg, Switzerland; pre-gold-coated samples only, 60 to $100 \mathrm{~nm})$.

To describe ossicle orientation in the asteroid skeleton, we used anatomical conventions as described in Fau \& Villier (2018): (1) the actinal surface (adoral) vs. the abactinal surface (aboral); (2) the abradial direction that points toward the radial plane of symmetry vs. the abradial direction that points away from the radial plane of symmetry; and (3) the proximal direction toward the centre of the disc vs. the distal direction toward the tip of the arm.

The anatomy of asteroid ossicles was described previously only by a few authors (Turner \& Dearborn, 1972; Blake, 1973; Gale, 2011). As Blake (1973) and Turner \& Dearborn (1972) based their nomenclature on only three families, all of them belonging to the order Paxilosida, we followed the nomenclature proposed in Gale (2011), including the modifications proposed by Fau \& Villier (2018), as well as new modifications and additions proposed herein (Table 2). Anatomical terms and abbreviations present in Table 2 are provided in italics in the text.

\section{PHYLOGENETIC METHODS}

The character/taxon matrix is composed of 115 morphological characters coded for 31 taxa, 29 forcipulatacean taxa and two outgroups, and is assembled in MESQUITE (see Appendix 1 for character description and Supporting Information File $\mathrm{S} 2$ for full character matrix). The matrix was coded and optimized, after phylogenetic analysis, through MESQUITE (Maddison \& Maddison, 2018). The matrix is $92 \%$ complete (fraction of character applicable and not missing). All multistate characters were unordered. The parsimony analysis was performed with PAUP* 4.0 (Swofford, 2002), using the heuristic search [(tree bisection-reconnection (TBR) - algorithm, stepwise addition of taxa for initiation]. Characters were all treated with equal weight. Trees are unrooted with default basal polytomy.

\section{RESULTS}

The heuristic search finds 30 most parsimonious trees with a length of 353 steps. The consistency index (CI) is 0.3966 and the retention index $(\mathrm{RI})$ is 0.6830 . The strict consensus of the 30 most parsimonious trees (Fig. 2) shows good support for several groups, but 


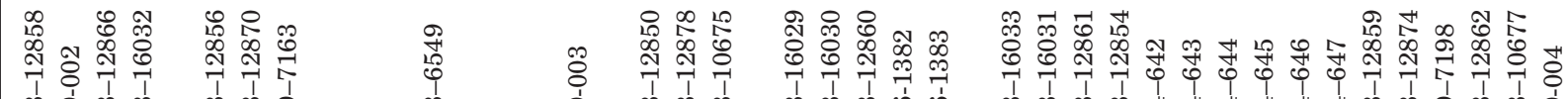

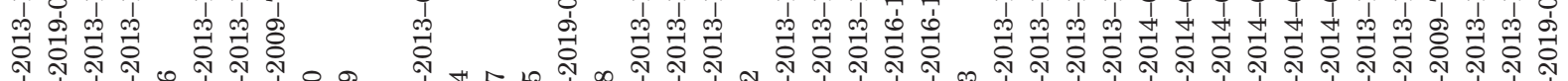

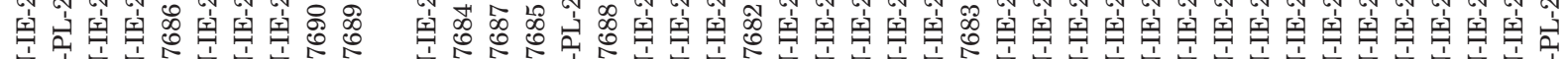

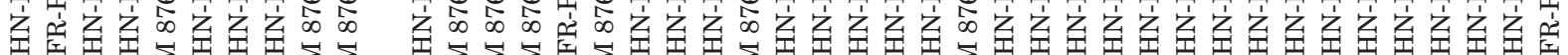

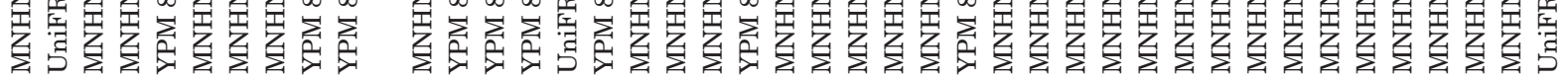

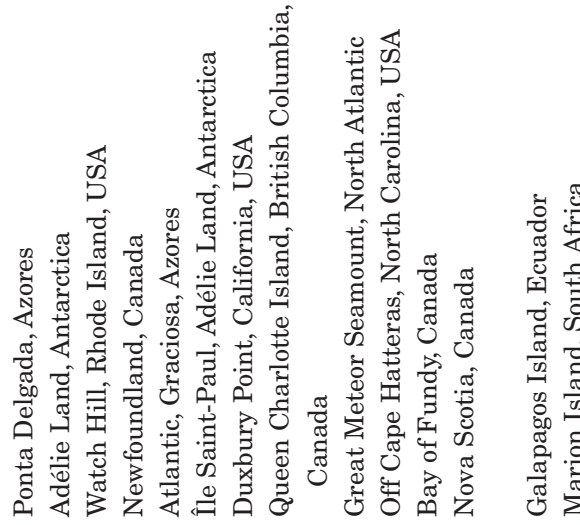

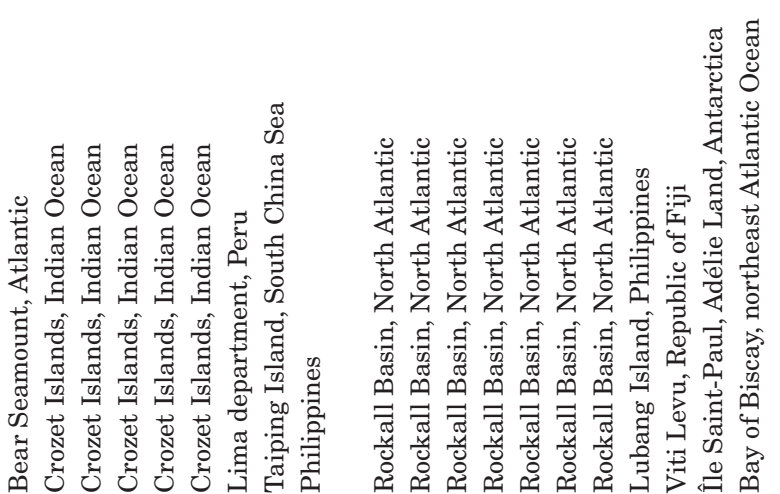

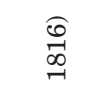

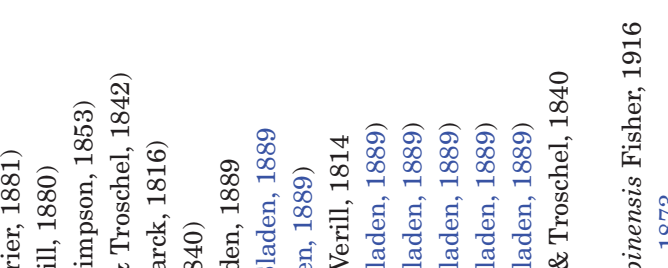

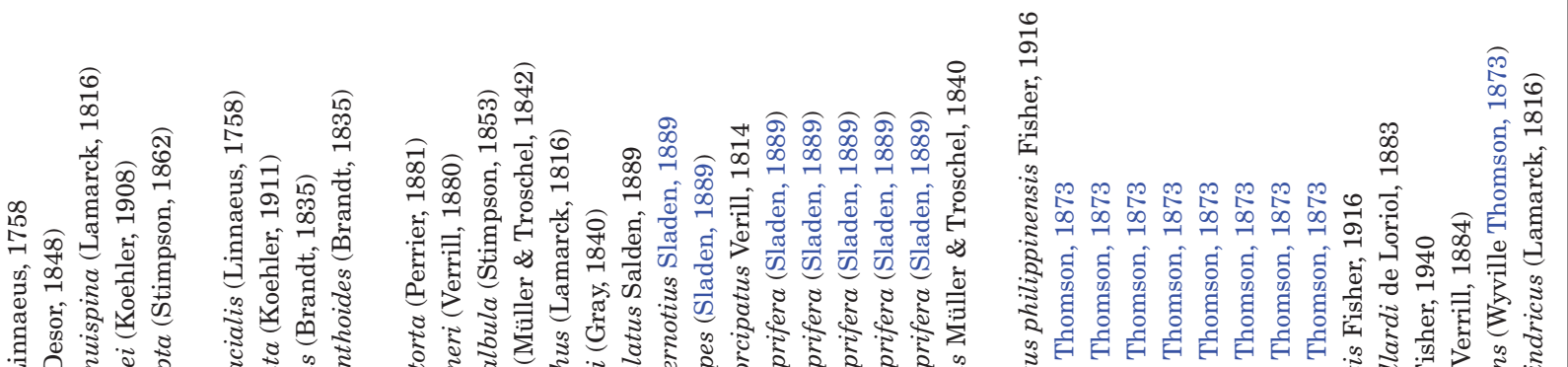

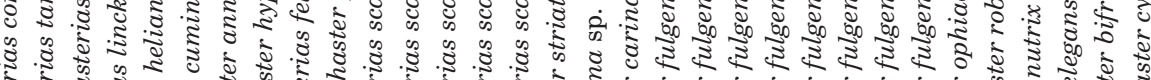

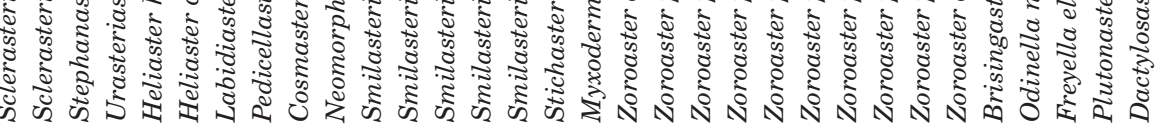

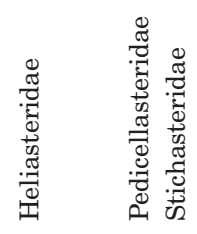

0
$\frac{\pi}{0}$
0
0
00
0
0
0
0
N.

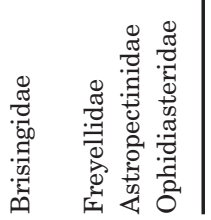


some uncertainties remain (i.e. within Zoroasteridae, Stichasteridae and Asteriidae).

Forcipulatacea is supported by seven synapomorphies and high bootstrap value ( $>95 \%)$. The base of the tree is a polytomy that includes Zoroasteridae, Brisingida and a clade containing all other Forcipulatacea (Fig. 2). Zoroasteridae and Brisingida are strongly supported as monophyletic with 15 and 13 synapomorphies, respectively, and bootstrap values of $100 \%$. However, the four species of Zoroasteridae form an unresolved polytomy. In the Brisingida clade, the Brisingidae is retrieved (Odinella nutrix + Brisingaster robillardi) as opposed to the Freyellidae (Freyella elegans). The families Asteriidae and Stichasteridae are retrieved as monophyletic and are sister-taxa (Fig. 2). Asteriidae are supported by only one unambiguous synapomorphy (i.e. the presence of wreath organ) and Stichasteridae are only supported by ambiguous synapomorphies. The Asteriidae is divided into two clades, a clade containing Asterias forbesi, A. rubens and Pisaster ochraceus on one side (clade A) and the remaining asteriids minus Leptasterias compta and Leptasterias sp. on the other side (clade B; Fig. 2). The genera Sclerasterias and Leptasterias are not retrieved as monophyletic. The two species Heliaster cumigi and $H$. helianthus support Heliaster as monophyletic. The only Pedicellasteridae present in this analysis, Pedicellaster hypernotius, arises as the sister to all Forcipulatacea minus Brisingida and Zoroasteridae (Fig. 2).

\section{SYNAPOMORPHIES OF THE PRIMARY CLADES}

Homoplasy is widespread across the matrix (Fig. 3). Characters are mapped on the strict consensus tree in MESQUITE (Maddison \& Maddison, 2018). A careful character by character analysis is conducted to determine the best non-ambiguous synapomorphies or the least homoplastic synapormorphies. A list of select synapomorphies are presented here for the clades Forcipulatacea, Zoroasteridae, Brisingida, Stichasteridae and Asteriidae, and non-ambiguous synapomorphies are highlighted by an asterisk * preceeding the character number (for character descriptions see Appendix 1; see Supporting Information, Figs S1-S10).

\section{Clade Forcipulatacea}

9. The articulation area doda of the odontophore is linked to the first ambulacral (Figs 4A, B, 5B, D).

*16. On the first ambulacral, the articulation areas procoa and dicoa are nearly parallel (Fig. 5; see Supporting Information, Fig. S2).

*22. On the oral, the rvg is in proximal position compare to the abiim (Fig. 6).
35. The articulation area with the superambulacrals are absent (bump present, but undifferentiated stereom in the Zoroasteridae; Fig. 7E, L).

36. The superambulacrals are absent (present, but reduced in the Zoroasteridae; Fig. 7L).

*51. Furrow spines are absent.

*99. Presence of forcipulate pedicellariae.

\section{Clade Brisingida}

*3. Partial fusion of the oral frame ossicles (orals, first ambulacrals and odontophores) forming a rigid ring (Figs 4A, B, 8C, D).

*6. The odontophore is longer than wide (Fig. 4B, E; see Supporting Information, Fig. S1G, J).

11. The ratio between the length and the height of the distal process of the first ambulacral is between 0.9 and 1.7 (convergent with the Asteriidae and the Stichasteridae; Fig. 5H).

12. The ratio between the length and the height of the proximal process of the first ambulacral is between 4 and 6 (convergent with Sclerasterias; Fig. $5 \mathrm{H})$.

*20. The articulation iioa is in abactinal position compare to the muscle insertion aciim (Fig. $6 \mathrm{~F}$; see Supporting Information, Figs S3, S4).

25. Presence of four or more enlarged spine bases on the orals.

28. Ambulacral with strongly arched abactinal profile (convergent with the Asteriidae; Fig. 7I).

32. Furrow on ambulacrals present, but irregular (Fig. 7H).

43. Muscles insertions dadam and padam (on adambulacrals) are approximately of equal sizes (convergent with some asteriids; Fig. 7T).

46. Crest between the muscles insertions dadam and padam (on adambulacrals) present (convergent with the Zoroasteridae; Fig. 7O, T).

54 . Actinals absent or reduced and loose in the dermal tissues (convergent with Labidiaster annulatus and Pycnopodia helianthoides).

62. Presence of only one row of marginals (convergent with the Zoroasteridae).

*100. Straight pedicellariae absent.

\section{Clade Zoroasteridae}

*2. Presence of a deeply sunken actinostome.

*8. Articulation areas poda and doda fused (on the odontophore; Fig. 4C, D).

*19. Orals, presence of teeth on the interoral articulation iioa (Fig. 6G).

35. The articulation area with the superambulacrals is limited to the presence of a bump with undifferentiated stereom (Fig. 7L). 
Table 2. List of the terms and abbreviations used in this paper, modified from Fau \& Villier (2018). Terms and abbreviations preceded by an asterisk * are specific to this paper. In the second column, abbreviations used by Gale (2011) when they differ, or when the structures were not named (-)

\begin{tabular}{|c|c|c|}
\hline Terms/abbreviation & Gale (2011) & Definition \\
\hline 1st podial basin & 1 st tf & $\begin{array}{l}\text { on the oral ossicle, area between the proximal and the distal } \\
\text { process where the first tube feet lie. generally associated with } \\
\text { denser and flatter stereom }\end{array}$ \\
\hline abiim & & interoral abactinal muscle \\
\hline abtam & & transverse abactinal interambulacral muscle \\
\hline aciim & & interoral actinal muscle \\
\hline actam & & transverse actinal interambulacral muscle \\
\hline base (of the ambulacrals) & & actinal part of the ambulacrals, as defined by Gale (2011) \\
\hline body (of the oral ossicle) & - & $\begin{array}{l}\text { actinal part of the ossicle bearing the spines, the odom and aciim } \\
\text { muscles on the interradial side, and the iioa articulation }\end{array}$ \\
\hline bp & & basal piece (on forcipulate pedicellariae) \\
\hline bump & sos & $\begin{array}{l}\text { spine attachment structure, consists of an articulation area at } \\
\text { the top of a bulge }\end{array}$ \\
\hline canine & - & $\begin{array}{l}\text { canine shaped like tooth on crossed forcipulate pedicellariae (de- } \\
\text { scribed in (Chia \& Amerongen, 1975) }\end{array}$ \\
\hline cra & - & carinal-radial articulation \\
\hline \multicolumn{3}{|l|}{ *crest (on ambulacral head) } \\
\hline dada & ada 2 , ada 3 & $\begin{array}{l}\text { ambulacral/adambulacral articulation (distal on the ambulacral, } \\
\text { proximal on the adambulacrals) }\end{array}$ \\
\hline dadam & & distal ambulacral/adambulacral muscle, on the ambulacrals \\
\hline *diastema & - & $\begin{array}{l}\text { gap between the distal teeth and median teeth on crossed } \\
\text { forcipulate pedicellariae }\end{array}$ \\
\hline dicoa & dcoa & $\begin{array}{l}\text { trace on the oral plates of the articulation between the oral and } \\
\text { the first ambulacral ossicle }\end{array}$ \\
\hline dicoam & - & oral/first ambulacral distal muscle insertion, on the oral \\
\hline distal process & $\operatorname{dcp}$ & distal process of the first ambulacral \\
\hline distal teeth & - & $\begin{array}{l}\text { teeth in distal position on crossed forcipulate pedicellariae (de- } \\
\text { scribed in (Chia \& Amerongen, 1975) }\end{array}$ \\
\hline doda & & distal oral/odontophore articulation on the oral \\
\hline *dph (on ambulacrals) & - & $\begin{array}{l}\text { distal process height, measure taken from the top of the teeth to } \\
\text { the end of the furrow or to the tip of the distal process when } \\
\text { the furrow is absent }\end{array}$ \\
\hline furrow & - & $\begin{array}{l}\text { furrow on the distal process of the first ambulacrals and on the } \\
\text { shaft of ambulacrals }\end{array}$ \\
\hline head (of the ambulacrals) & & abactinal part of the ambulacrals, as defined by Gale (2011) \\
\hline iia & - & internal interradial actinals \\
\hline iioa & & interoral articulation \\
\hline interada & adada & interadambulacral articulation \\
\hline interadam & adadam & interadambulacral muscle \\
\hline lia & & longitudinal interambulacral articulation \\
\hline $\lim$ & & longitudinal interambulacral muscle \\
\hline medial projection & - & $\begin{array}{l}\text { projection on crossed forcipulate pedicellariae, described in (Chia } \\
\text { \& Amerongen, 1975) }\end{array}$ \\
\hline median teeth & - & $\begin{array}{l}\text { teeth in median position on crossed forcipulate pedicellariae, can } \\
\text { be on the medial projection, described in (Chia \& Amerongen, } \\
\text { 1975) }\end{array}$ \\
\hline odom & & odontophore-oral muscle \\
\hline orada & & oral-adambulacral articulation, on the oral \\
\hline oradam & oradm & oral-adambulacral muscle, on the oral \\
\hline *pab (on the oral) & & proximal angle of the body \\
\hline
\end{tabular}


Table 2. Continued

\begin{tabular}{|c|c|c|}
\hline Terms/abbreviation & Gale (2011) & Definition \\
\hline pada & $\begin{array}{l}\text { ada } 1, \text { ada } 1 \mathrm{a}, \\
\text { ada1b }\end{array}$ & $\begin{array}{l}\text { ambulacral-adambulacral articulation, (proximal on the ambula- } \\
\text { cral, distal on the adambulacral) }\end{array}$ \\
\hline padam & & proximal ambulacral-adambulacral muscle, on the ambulacral \\
\hline plateau & - & $\begin{array}{l}\text { flat area at the end of the abactinal ramus edge, generally dis- } \\
\text { tinct from the latter by a change of slope. bear the doda articu- } \\
\text { lation on the interradial side, and the complex dicoa / dicoam } \\
\text { on the radial side }\end{array}$ \\
\hline poda & & proximal odontophore-oral articulation \\
\hline *pph (on ambulacrals) & - & $\begin{array}{l}\text { proximal process height, measure taken from the top of the teeth } \\
\text { to the proximal-most part of the articulation procoa }\end{array}$ \\
\hline procoa & pcoa & proximal oral-first ambulacral articulation, on the orals \\
\hline procoam & - & proximal oral-first ambulacral muscle on the oral \\
\hline proximal process & pcp & proximal process of the first ambulacral \\
\hline pustule & ads, fs, osp & $\begin{array}{l}\text { spine attachment structure, consist of a notch completely or par- } \\
\text { tially surrounded by an articulation area at the top of a bulge }\end{array}$ \\
\hline ramus & apo & $\begin{array}{l}\text { abactinal extension of the oral ossicle, bearing the abiim muscle } \\
\text { and the poda articulation on the interradial side, and the } \\
\text { complex Procoa / procoam on the radial side of the ossicle. Also } \\
\text { called apophyse by Turner \& Dearborn (1972), and Gale (2011) }\end{array}$ \\
\hline ria & - & radial-interradial articulation \\
\hline riom & & interoral muscle \\
\hline rng & & passageway of the nervous oral ring \\
\hline rvg & & $\begin{array}{l}\text { groove along the oral ossicles in which lies the ring canal of the } \\
\text { ambulacral system }\end{array}$ \\
\hline sa & & superambulacral \\
\hline shaft (of the ambulacrals) & & middle part of the ambulacrals, as defined by Gale (2011) \\
\hline teeth & de & $\begin{array}{l}\text { imbricating teeth and socket structures, on the ambulacral head. } \\
\text { Similar structure can appear on the interradial side of the } \\
\text { orals and of adambulacrals of the adoral carina }\end{array}$ \\
\hline *tl (on ambulacrals) & - & $\begin{array}{l}\text { teeth length, length of the head measured at the base of the } \\
\text { teeth on ambulacrals }\end{array}$ \\
\hline wings & - & $\begin{array}{l}\text { proximal and distal extensions at the base of the ambulacral for } \\
\text { attachment of the ambulacral/adambulacral muscles (Turner } \\
\text { \& Dearborn, 1972) }\end{array}$ \\
\hline
\end{tabular}

36. The superambulacrals are present but reduced (Fig. 7L).

*39. Presence of teeth on the interradial surface of the adambulacrals of the adoral carina (Fig. 8B).

46. Crest between the muscles insertions dadam and padam (on adambulacrals) present (convergent with Brisingida) (Fig. 7U).

*47. Presence of alternatively carinate and noncarinate adambulacrals (Fig. 8B).

*49. At least four primary spines on adambulacrals (Fig. 7N).

62. Presence of only one row of marginals (convergent with the Brisingida; see Supporting Information, Fig. S8).

69. Presence of secondary spines attached on bump on inferomarginals (convergent with Neomorphaster forcipatus).
84. Abactinals strongly arched (convergent with Stichasteridae).

89. Carinals with more than four articular facets (convergent with Heliaster, and probably with other groups not considered in this analysis).

*104. Crossed pedicellariae absent.

$* 113$. The madreporite is embedded in a special cavity of the adjoining interradial.

\section{Clade Stichasteridae}

58. Actinals with two or three primary spines.

77. Presence of at least four primary spines on superomarginals (Fig. 9F). 


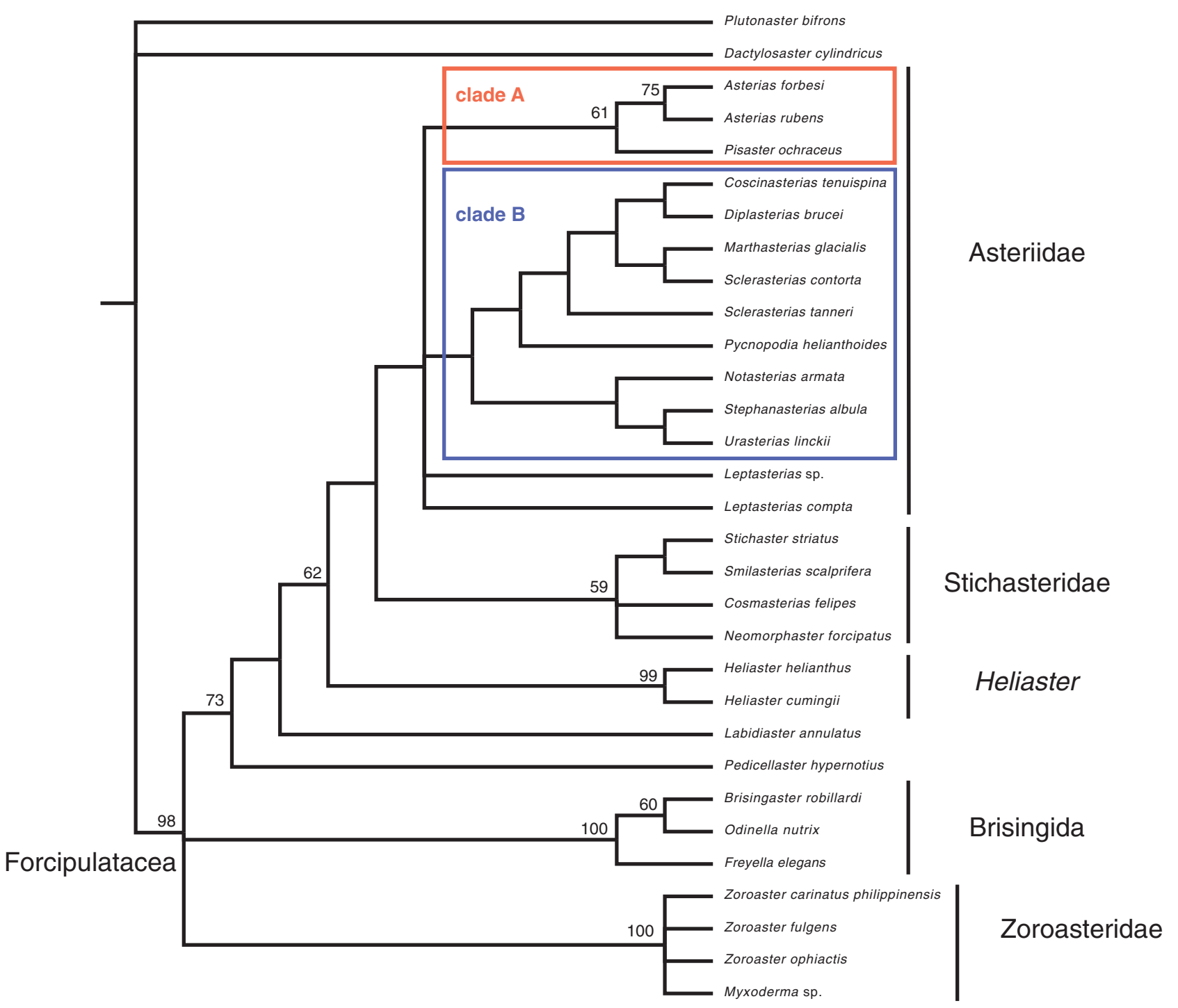

Figure 2. Strict consensus of the 30 most parsimonious trees found. Bootstrap values above $50 \%$ are indicated at the nodes.

80. Wall skeleton compact, with overlapping plates (i.e. actinals, marginals, abactinals and carinals; convergent with the Zoroasteridae; Fig. 9F).

84. Abactinals strongly arched (convergent with the Zoroasteridae).

\section{Clade Asteriidae}

28. Ambulacral with strongly arched abactinal profile (convergent with the Brisingida) (Fig. 7B, D)

29. The muscle insertion lim represent more than $40 \%$ of the ossicle height and finishing under the actam (convergent with Labidiaster annulatus) (Fig. 7B, D)

67 . Round pustule absent on the inferomarginals (presence only of keyhole pustules; see Supporting Information, Figs S8, S9).
79. Abactinals differentiate with at least two level of plates (convergent with Pedicellaster hypernotius; Fig. 9).

81. Abactinals, intercalary inter-arc ossicles present (convergent with Pedicellaster hypernotius; Fig. 9E).

*110. Wreath organ present (characters number 60, 83 and 91 are also on wreath organs, see Appendix 1)

\section{DISCUSSION}

\section{ASTERIIDAE}

Asteriidae is the most diverse family of forcipulatacean sea stars, representing half of the taxonomic diversity of the group. Their morphology is overall consistent. 


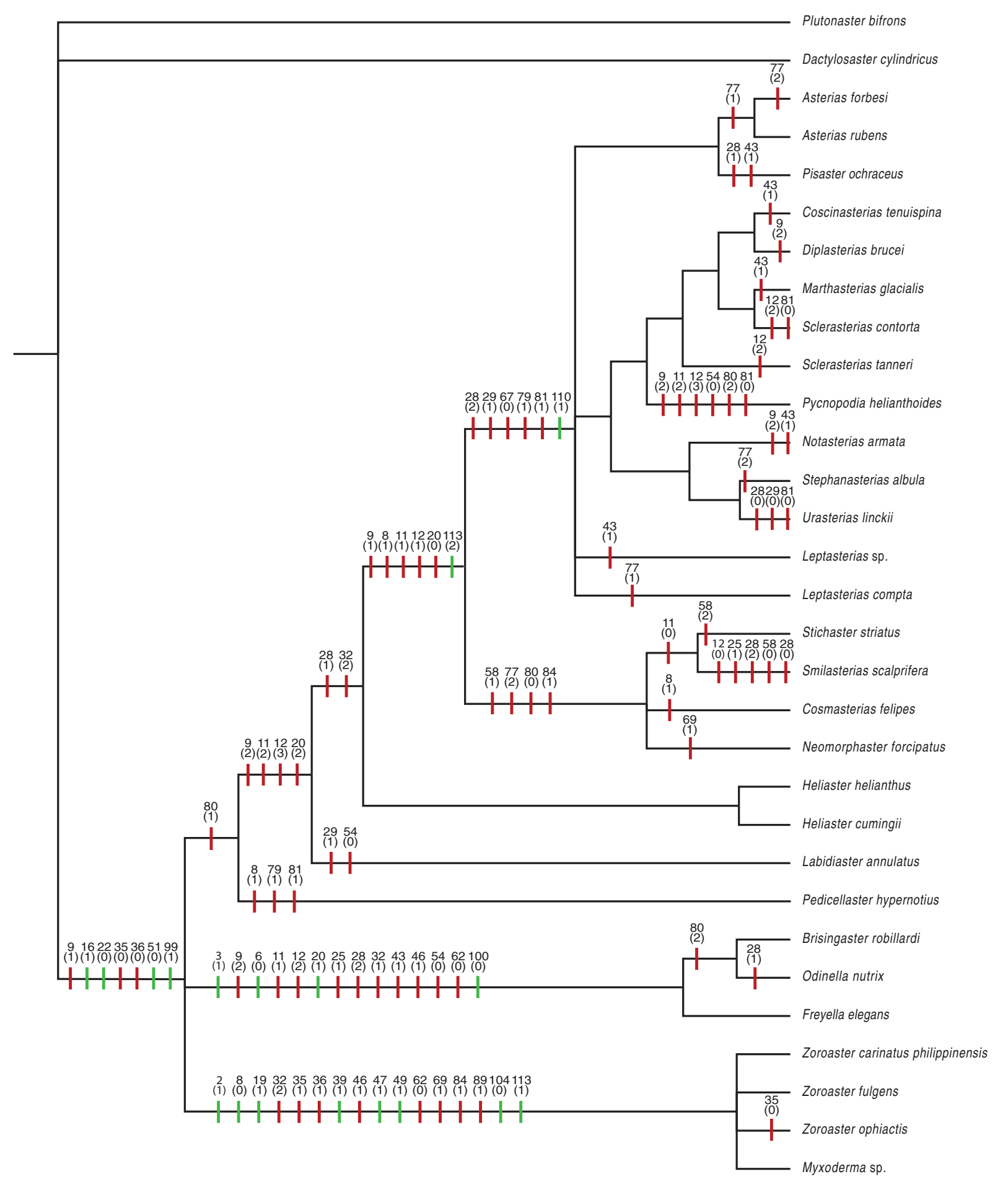

Figure 3. Strict consensus tree with selected synapomorphies mapped on the nodes. See Appendix 1 for full descriptions of characters. Characters in green are non-ambiguous synapomorphies (i.e. they occur only once in the tree), and red characters are ambiguous synapomorphies, (i.e. they occur at least two times independently in the tree). 


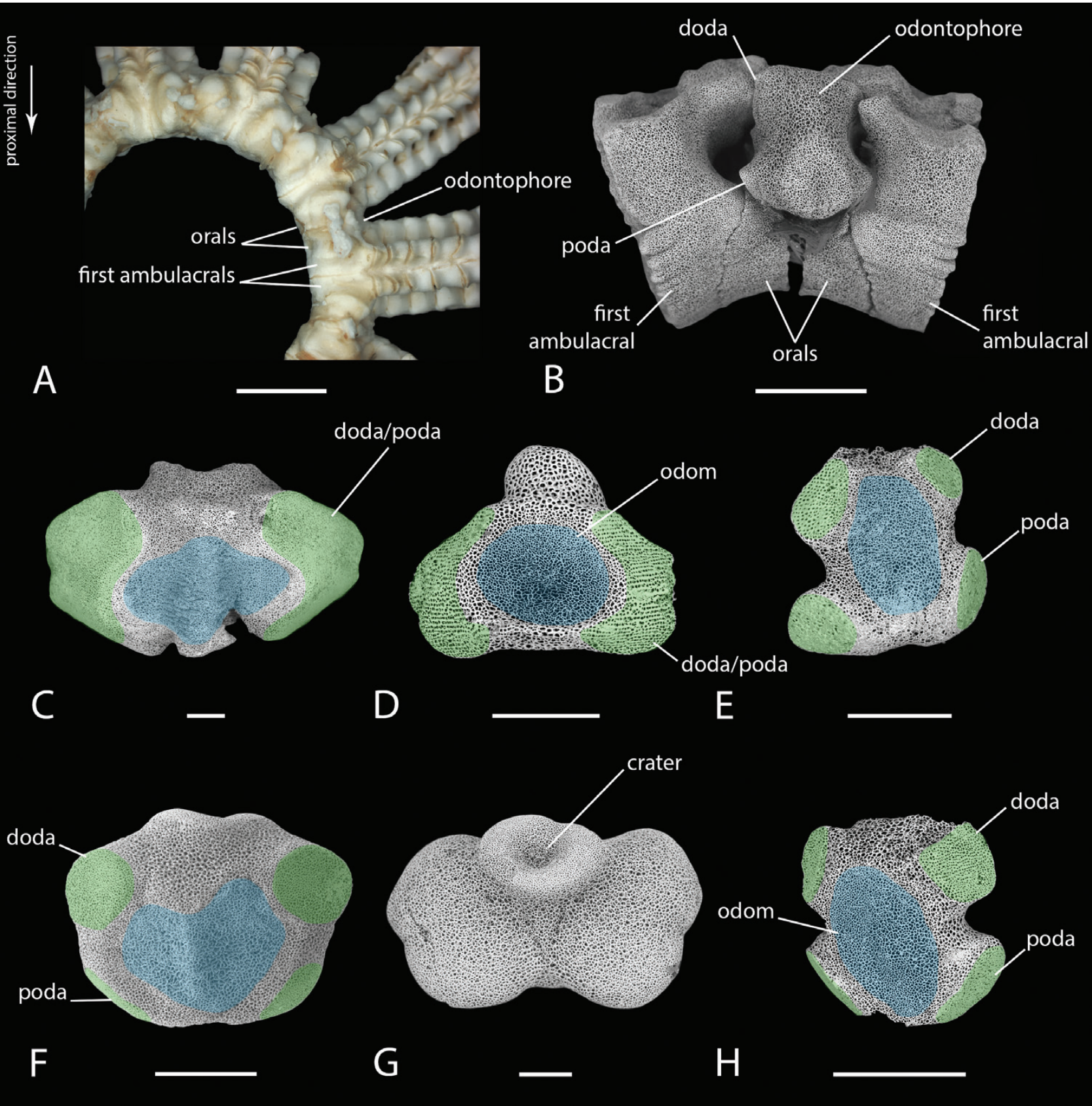

Figure 4. Oral ring in abactinal view (A) and scanning electron microscopy (SEM) images of odontophores in abactinal view (B, G) and actinal view (C-F, H). A, photography of the oral ring of Freyella elegans (MNHN-IE-2013-12862); B, part of the oral ring of Brisingaster robillardi (MNHN-IE-2009-7198); C, Myxoderma sp. (MNHN-IE-2013-16033); D, Zoroaster carinatus philippinensis (MNHN-IE-2013-16031); E, Odinella nutrix (MNHN-IE-2009-7198); F, Sclerasterias tanneri (YPM No 87684); G, Diplasterias brucei (MNHN-IE-2013-16032); H, Labidiaster annulatus (MNHN-IE-2013-12850). Coloured areas indicate the presence of a differentiated stereom. In blue: insertion of the muscle odom; in green: articulation poda and doda. See Table 2 for abbreviations. Scale bars: $5 \mathrm{~mm}(\mathrm{~A}), 1 \mathrm{~mm}(\mathrm{~B}), 500 \mu \mathrm{m}(\mathrm{C}-\mathrm{H})$. 


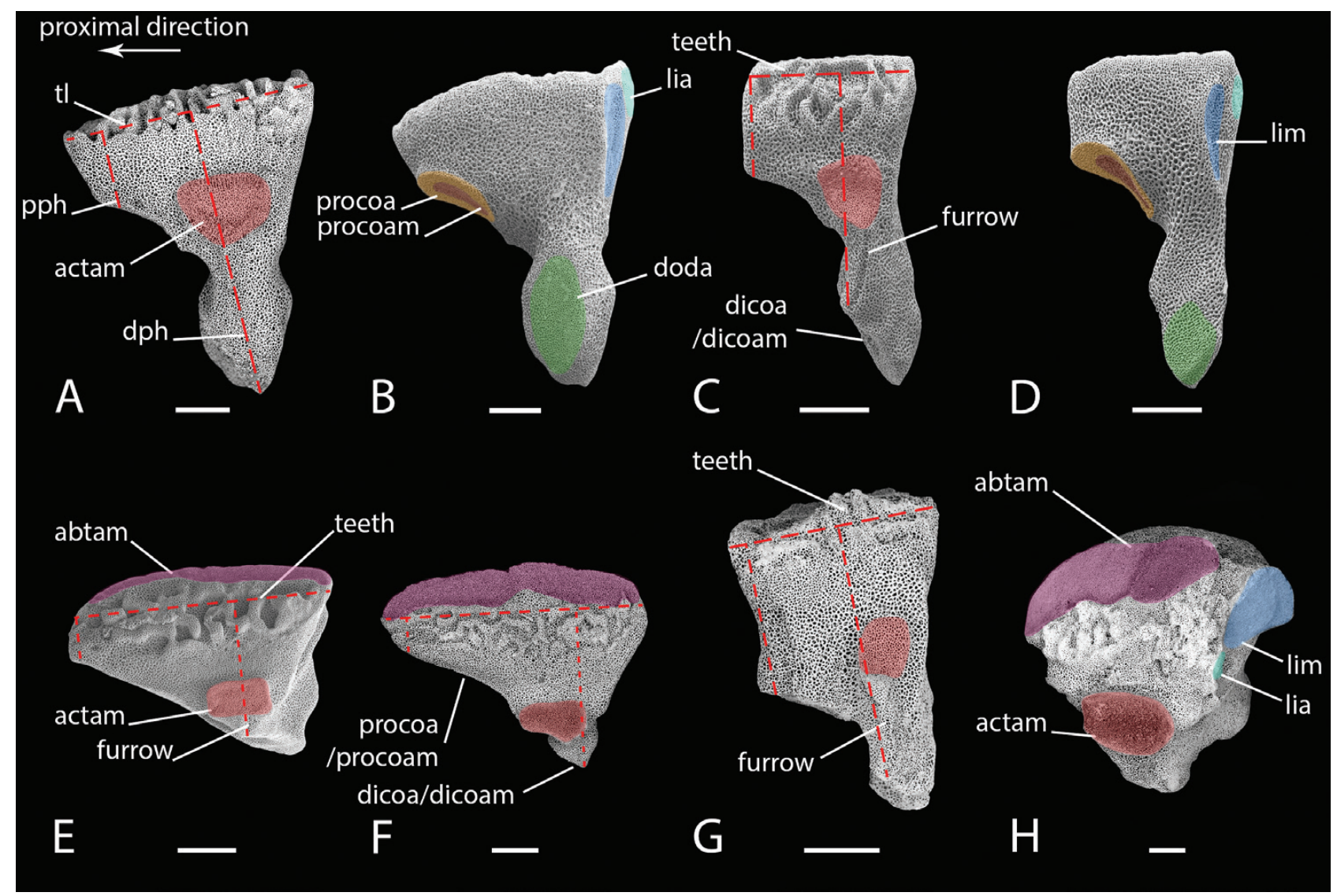

Figure 5. Scanning electron microscopy (SEM) images of first ambulacrals in actinal view (A, C, E-H) and abactinal view (B, D). A, B, Notasterias armata (MNHN-IE-2009-7163); C, D, Smilasterias scalprifera (MNHN-IE-2013-12860); E, Pycnopodia helianthoides (YPM No 87689); F, Labidiaster annulatus (MNHN-IE-2013-12850); G, Zoroaster carinatus philippinensis (MNHN-IE-2013-16031); H, Freyella elegans (MNHN-IE-2013-12862). Measurements used in characters 11,12 and 13 are in red dashed lines on the actinal views: teeth length $(t l)$, proximal process height $(p p h)$ and distal process height $(d p h)$. Coloured areas indicate the presence of a differentiated stereom. In red: insertion of the muscle actam; in purple: insertion of the muscle abtam; in dark blue: insertion of the muscle lim; in brown: insertion of the muscle procoam; in orange: articulation procoa. in light blue: articulation lia; in green: articulation doda. Actinal to the bottom. See Table 2 for abbreviations. Scale bars: $500 \mu \mathrm{m}$.

All of the 14 asteriids sampled for this study exhibit similar external features, such as a reticulate skeleton, four rows of tube feet, the presence of an adoral carina and wreath organs. The consistency of their anatomy is most apparent in the ossicles of the oral frame and of the ambulacral groove (Figs 6A-C, 7A-E; Supporting Information, Figs S2, S3, S5). The odontophore is characterized by a butterfly shape (Fig. 4F, G), and the orals have a round body, with a relatively long ramus (Fig. 6A-C). Ambulacrals and adambulacrals are proximodistally compressed (Fig. 7). However, asteriids share many of these characteristics with stichasterids, making it difficult to distinguish with certainty the oral ossicles of an asteriid from those of a stichasterid ((Fig. 6A-D)). This problem applies also to the odontophores, first ambulacrals and adambulacrals (Figs 5A-D, 7). Two synapomorphies of the ambulacrals allow the distinction between Asteriidae and Stichasteridae: asteriids have a strongly arched abactinal profile and the muscle insertion lim is elongated (characters 28 and 29; for description of the characters see Appendix 1).

Other differences are identified in the wall skeleton. The reticulate wall skeleton of asteriids is always made of cruciform marginals and carinals (except for taxa with a reduced skeleton, such as Pycnopodia helianthoides and Urasterias linckii). The organization, density and shape of the abactinal series distinguish asteriids from other forcipulataceans (Fig. 9). We observed, when comparing the organization of the abactinal ossicles in our sample to the drawings of Fisher (1928), that the abactinals, as a general pattern, are not organized in rows, but rather in arcs. Indeed, the abactinals join the carinals to the superomarginals to form transversal arcs that connect 


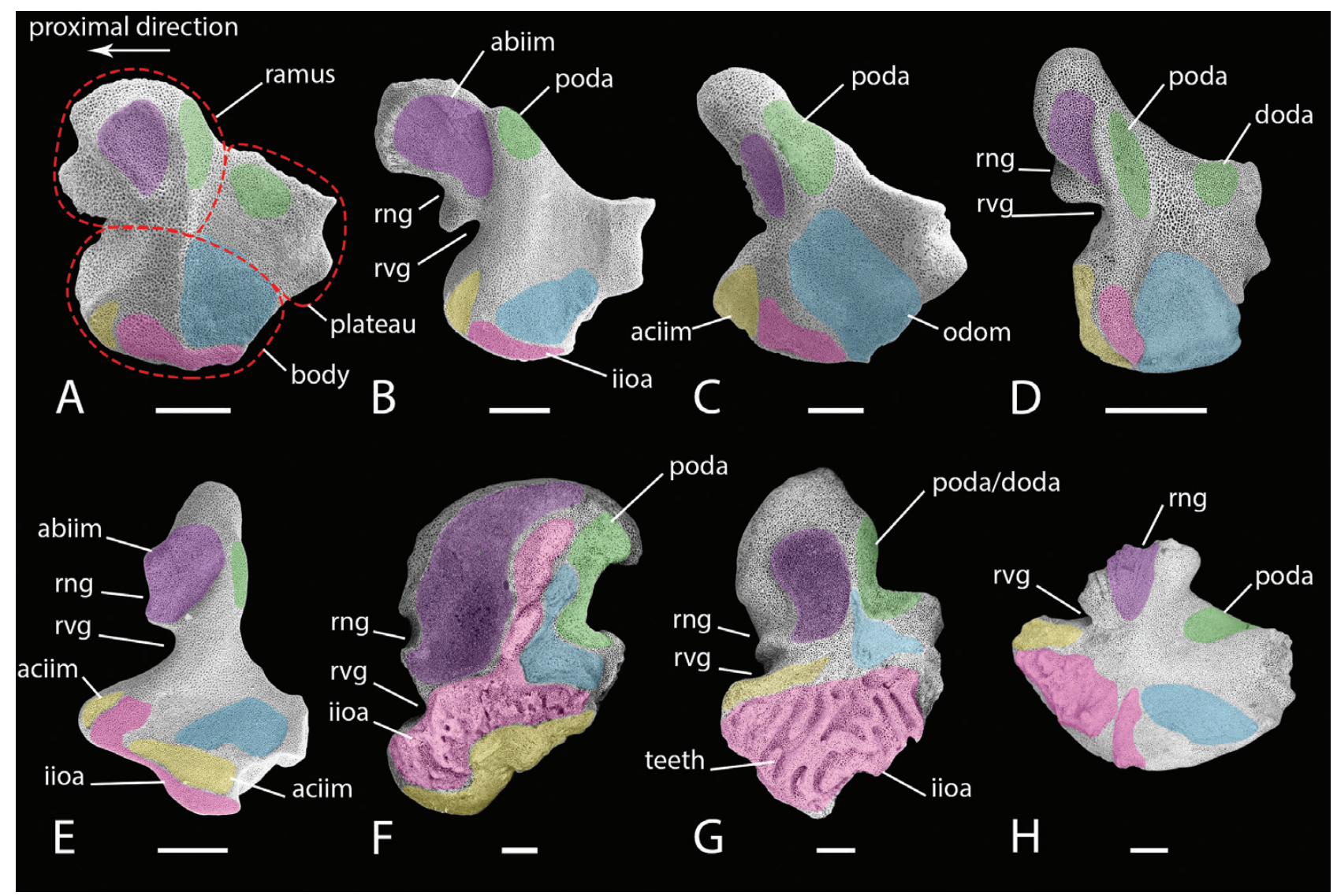

Figure 6. Scanning electron microscopy (SEM) images of oral ossicles in interradial view. A, Sclerasterias tanneri (YPM No 87684); B, Pycnopodia helianthoides (YPM No 87689); C, Notasterias armata (MNHN-IE-2009-7163); D, Smilasterias scalprifera (MNHN-IE-2013-16029); E, Heliaster cumingi (YPM No 87688); F, Freyella elegans (MNHN-IE-2013-12862); G, Zoroaster fulgens (MNHN-IE-2013-12861); H, Plutonaster bifrons (MNHN-IE-2013-10677). Coloured areas indicate the presence of a differentiated stereom. In purple: insertion of the muscle abiim; in yellow: insertion of the muscle aciim; in blue: insertion of the muscle odom; in pink: articulation iioa; in green: articulation poda and doda. Actinal to the bottom. See Table 2 for abbreviations. Scale bars: $500 \mu \mathrm{m}$.

to form a network, as it was described by Perrier (1885: 107). These arcs can be lost when the abactinal mesh is denser. Abactinals are added continuously during ontogeny everywhere along the arms to fill the gaps. They are, therefore, diachronic. Abactinals differentiate according to their relative size, their relationships with formerly existing plates and the presence or absence of spines. We can recognize at least two levels of differentiation in all asteriids in our sample: 'principal abactinals' and 'secondary abactinals'. Principal abactinals are interpreted as the oldest abactinals of the series, at least as compared to their closest neighbours along the arm. They are generally bigger than the secondary abactinals, they almost always bear at least one spine and they overlap the other abactinals with which they are in contact. Recently, Schwertmann et al. (2019) produced a $3 \mathrm{D}$ model of the skeleton of Asterias rubens, and argued that two different groups of abactinals (node and connecting ossicles) can be recognized based on their function in the skeleton. The node ossicles would be homologous with the principle abactinals we recognize here, and the connecting ossicles would be the secondary ossicles.

The abactinal arcs are formed by both principal and secondary abactinals. The arcs can be joined together by inter-arc ossicles, that are always secondary abactinals (Fig. 9E; characters 79 and 81; for a description of the characters see Appendix 1). The Stichasteridae differ from the Asteriidae in their abactinal organization. 


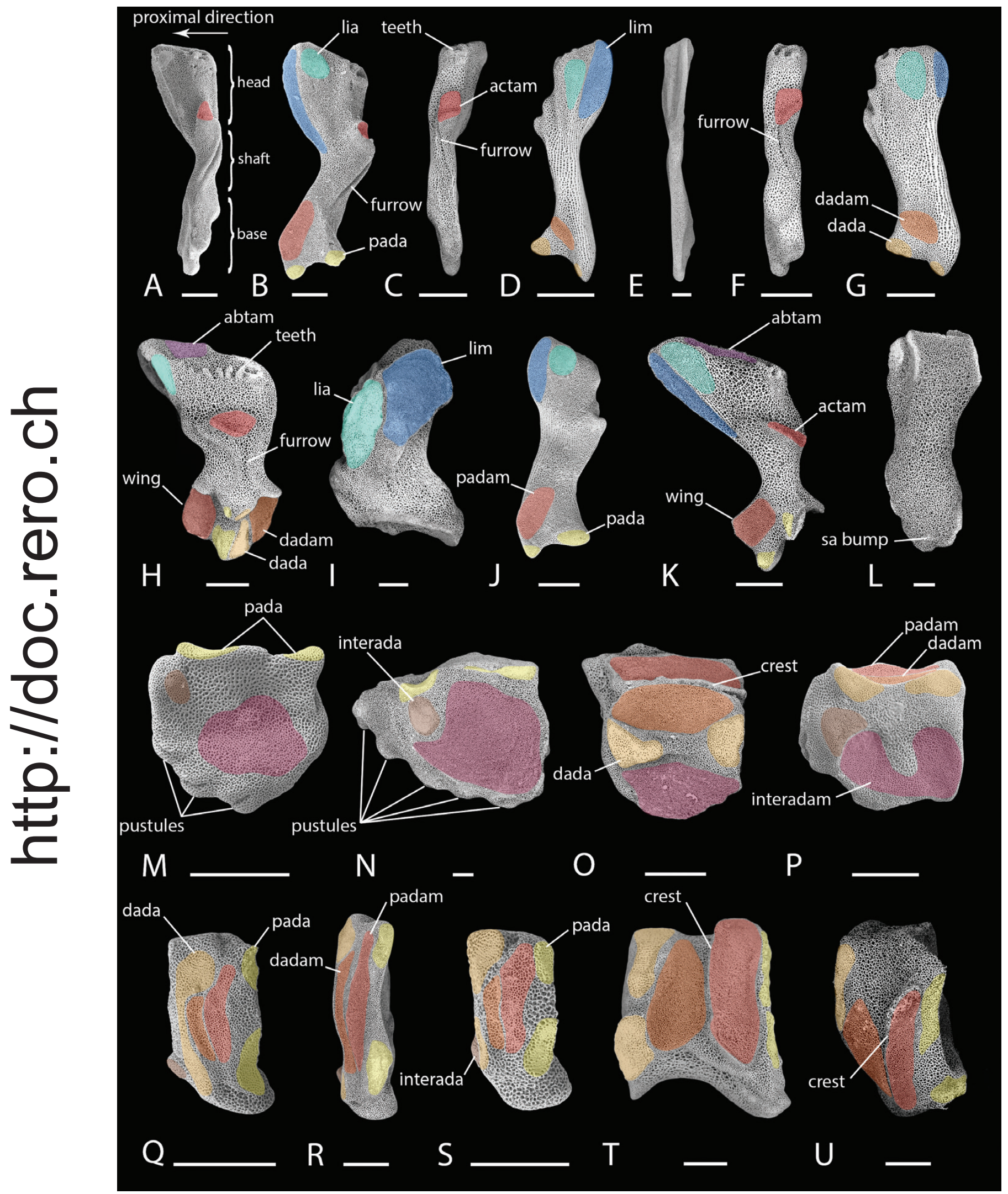



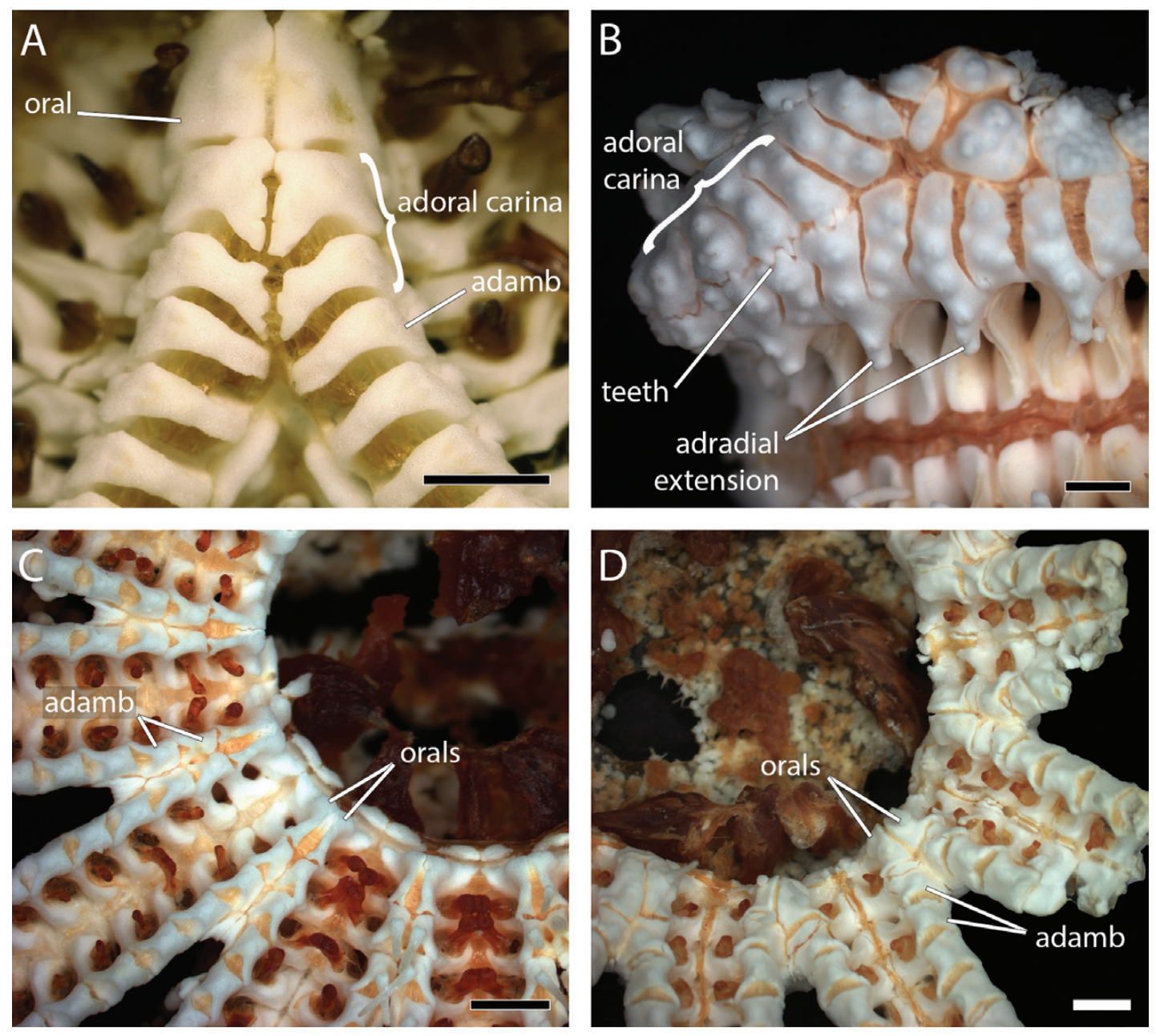

Figure 8. Oral frame of: A, Urasterias linckii (YPM No 87685); B, Myxoderma sp. (MNHN-IE-2013-16033); C, Odinella nutrix (MNHN-IE-2009-7198); and D, Freyella elegans (MNHN-IE-2013-12862). See Table 2 for abbreviations. Scale bars: $1 \mathrm{~mm}(\mathrm{~A}), 2 \mathrm{~mm}(\mathrm{~B}-\mathrm{D})$.

Stichasterids have a compact wall skeleton, with no noticeable differentiation between abactinals (Fig. 9F).

The most important synapomorphy that differentiates Asteriidae from all other Forcipulatacea is the presence of wreath organs. Wreath organs are a concentration of crossed pedicellariae around the spines that are organized into complex structure with dedicated muscles allowing the wreath of pedicellariae to move up and down the spines (Lambert et al., 1984). This is a specialized and complex structure unique to

Figure 7. Scanning electron microscopy (SEM) images of ambulacral ossicles (A-L) and adambulacral ossicles (M-U), in actinal view (A, C, F, H, K), abactinal view (E, L, Q-U), proximal view (B, J, O, P) and distal view (D, G, I, M, N). A, B, Pycnopodia helianthoides (YPM No 87689); C, D, Coscinasterias tenuispina (MNHN-IE-2013-12866); E, Marthasterias glacialis (MNHN-IE-2013-12870); F, G, Cosmasterias felipes (MNHN-IE-2013-10675); H, I, Brisingaster robillardi (MNHN-IE-2009-7198); J, Heliaster cumingi (YPM No 87688); K, Labidiaster annulatus (MNHN-IE-2013-12850); L, Myxoderma sp. (MNHN-IE-2013-16033); M, Stephanasterias albula (YPM No 87687); N, Myxoderma sp. (MNHN-IE-2013-16033); O, Brisingaster robillardi (MNHN-IE-2009-7198); P, Stichaster striatus (YPM No 87683); Q, Leptasterias compta (YPM No 87686); R, Marthasterias glacialis (MNHN-IE-2013-12870); S, Neomorphaster forcipatus (YPM No 87682); T, Freyella elegans (MNHN-IE-2013-12862); U, Zoroaster ophiactis (MNHN-IE-2013-12859). Coloured areas indicate the presence of differentiated stereom. In dark red: insertion of the muscle actam; in purple: insertion of the muscle abtam; in light red: insertion of the muscle padam; in orange: insertion of the muscle dadam; in dark blue: insertion of the muscle lim; in pink: insertion of the muscle interadam; in brown: articulation interada; in light blue: articulation lia; in light orange: articulation dada; in yellow: articulation pada. See Table 2 for abbreviations. Scale bars: $500 \mu \mathrm{m}$. 

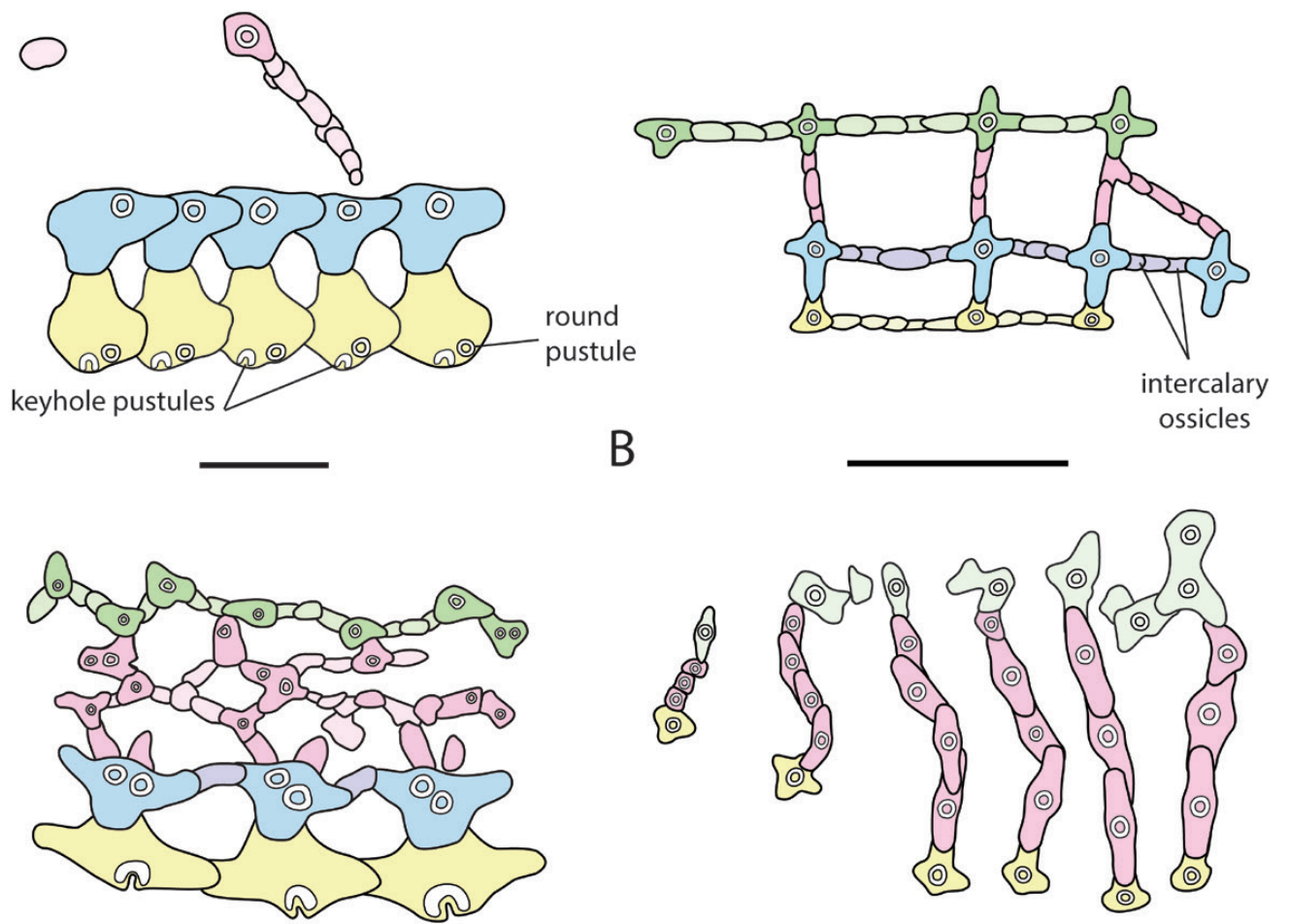

C

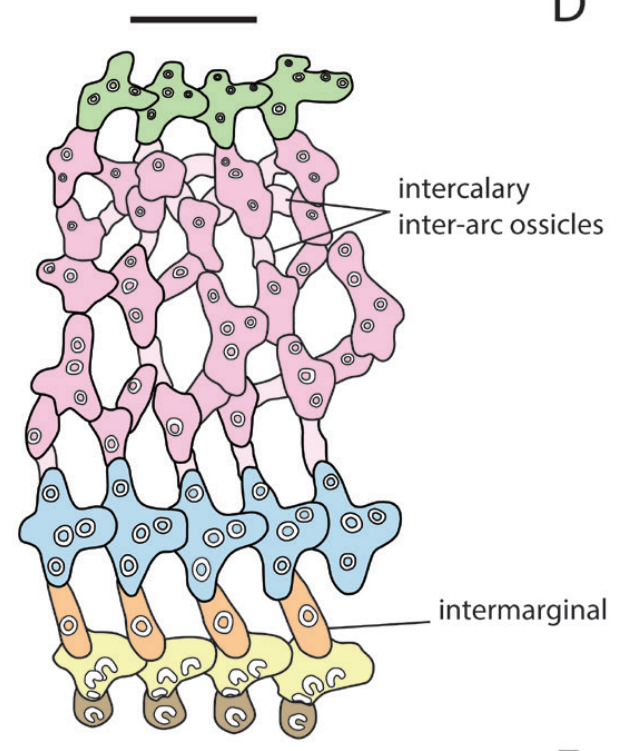

$E$

$\mathrm{F}$

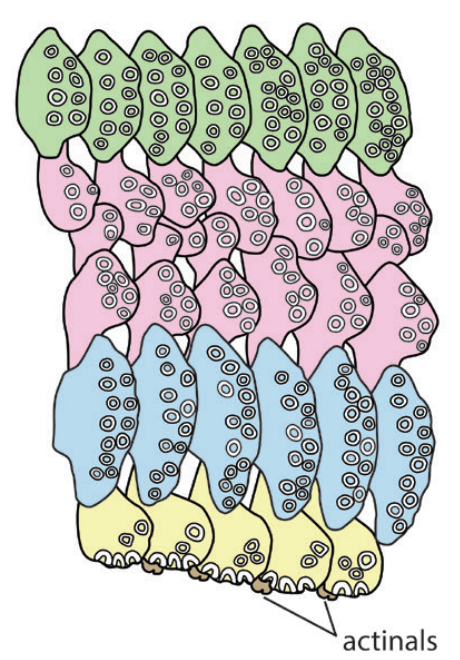

Figure 9. Wall skeleton arrangement along the arms of forcipulatids. A, Pycnopodia helianthoides (modified from: Fisher, 1928: pl. 79); B, Coronaster pauciporis (MNHN-IE-2014-80); C, Urasterias linckii (YPM No 87685); D, Brisingaster robillardi (MNHN-IE-2009-7198) E, Asterias forbesi (UniFR-PL-2019-002); F, Stichaster striatus (MNHN-IE-2013-12864). Proximal direction to the right, actinal to the bottom. Coloured areas indicate ossicle homology. In green: carinals; in pink: primary abactinals; in light pink: secondary abactinals; in blue: superomarginals; in orange: intermarginals; in yellow: inferomarginals; in brown: actinals. In lighter colour (green, blue and yellow) are differentiated plates of the carinals, superomarginals and inferomarginals. They are morphologically differentiated and generally do not bear spines. Note that no carinal series can be recognized in Brisingaster robillardi, and the light green plates represent the plate that are on top of the arm in the expected position for carinals. Actinal to the bottom. See Table 2 for abbreviations. Scale bars: 5 mm. 
the Asteriidae. All asteriids possess wreath organs around the inferomarginal spines and most taxa exhibit wreath organs around the superomarginal, abactinal and carinal spines as well. Some taxa have even developed wreath organs on actinals and adambulacral spines [i.e. Leptasterias compta, this study and Clark \& Downey (1992)]. A concentration of crossed pedicellariae around the spines also occurs in the Brisingida and Labidiaster annulatus. Mah (2000) reported wreath organs to be present in Labidiaster, Brisinga and Odinella. However, we argue that their cluster of crossed pedicellariae are not homologous to the wreath organs of the Asteriidae because the stalks of the pedicellariae are attached directly to the spines (Emson \& Young, 1994). In asteriids, by contrast, the stalks of the pedicellariae of the wreath organs are embedded in the outer layer of epidermis composing the wreath organ (Lambert et al., 1984). Therefore, the pedicellariae of Labidiaster, Brisinga and Odinella are completely independent of one another and do not form a united structure.

The Asteriidae is divided in two clades (Fig. 2): a clade restricted to Asterias rubens, Asterias forbesi and Pisaster ochraceus (clade A), and a clade containing all other asteriids, minus the genus Leptasterias (clade B). This topology differs greatly form the tree obtained by Mah \& Foltz (2011a), in which the phylogeny of the Asteriidae reflect their geographical repartition. Following the hypothesis of Mah \& Foltz (2011a), Stephanasterias albula and Pycnopodia helianthoides should be more closely related to clade A, instead of being scattered within clade $\mathrm{B}$.

\section{STICHASTERIDAE}

The family Stichasteridae was initially described by Perrier (1885) to group Zoroaster and Stichaster, based on the compact organization of the abactinal skeleton. Later on, a new family, the Zoroasteridae, was erected by Sladen (1889), and Zoroaster was, therefore, removed from the Stichasteridae (Perrier, 1894; Mortensen, 1927). The family Stichasteridae was ignored by Fisher (1928, 1930), who seemed to have considered it as a synonym of Asteriidae. Fisher's classification was followed by many subsequent authors (e.g. Clark \& Downey, 1992; Mah, 2000). Mah's (2000) first phylogenetic analysis of the Forcipulatacea failed to group together the three included sitchasterids, also included in his study (the genus Cosmasterias, Neomorphaster and Stichaster). However, recent molecular data supports a monophyletic Stichasteridae (Mah \& Foltz, 2011a).

Our analysis retrieves the Stichasteridae as monophyletic, but with low support, and no unambiguous synapomorphies. Although they are morphologically distinct, it has been difficult to define meaningful morphological characters that unite them. Sladen (1889: 430) qualified the morphology of the Stichasteridae as an intermediate between the Zoroasteridae and the Asteriidae. Our results confirm this statement and the resemblance/convergence with Zoroasteridae explain the absence of unambiguous synapomorphies for the Stichasteridae.

\section{ZOROASTERIDAE}

Zoroaster fulgens was described as an asteriid by Thomson (1873). Perrier (1884) then moved the genus Zoroaster to the new family Pedicellasteridae, before placing it one year later to a new family, Stichasteridae (Perrier, 1885). Four years later, Sladen (1889) erected the family Zoroasteridae and described two new genera, Cnemidaster and Pholidaster. Since then, the monophyly of Zoroasteridae has been widely accepted by the scientific community (e.g. Blake, 1987; Gale, 1987; Mah, 2000; Mah, 2007; Gale, 2011; Mah \& Foltz, 2011a; Mah \& Blake, 2012). The family comprises 35 extant species distributed in seven genera (Mah, 2019). Many phylogenetic studies support the Zoroasteridae in a basal position within Forcipulatacea (Blake, 1987; Gale, 1987; Mah, 2000; Mah \& Foltz, 2011a; Mah et al., 2015), and they have argued that they display plesiomorphic character associations intermediate between the Palaeozoic taxa and the Post-Palaeozoic taxa (Downey, 1970; Blake \& Elliott, 2003; Blake \& Hagdorn, 2003; Mah, 2007).

The Zoroasteridae is the best-supported clade in our analysis with 15 synapomorphies, of which eight are unambiguous synapomorphies. Nine of these were described by Fau \& Villier (2018) in their study of the anatomy of Zoroaster fulgens. Five of the six historical characters described by Fau \& Villier (2018) are synapomorphies of the clade: (1) presence of a deeply sunken actinostome (Fig. $8 \mathrm{~B}$; character $* 2$ ); (2) the presence of alternatively carinate and noncarinate adambulacrals (Fig. 8B; character $* 47$ ); (3) the presence of superambulacrals (character 36 ); (4) the presence of only one row of marginals (character 62); and (5) the absence of crossed pedicellariae (character*104). The number of tube feet rows was not included in the character matrix, but its distribution is known to be homoplastic, as many forcipulatacean sea stars exhibit four rows of tube feet proximally that are distally reduced to two rows (e.g. zoroasterids, pedicellasterids and paulasterids). Out of the six characters newly described by Fau \& Villier (2018), four are synapomorphies of the clade Zoroasteridae: (6) the articulation poda and doda on the odontophore are fused (Fig. 4C, D; character $8^{*}$ ); (7) the presence of teeth on the articulation iioa (Fig. 6G, character 19*); (8) the presence of teeth on the interradial surface of the adambulacral of the adoral carina (Fig. 8B; 
character $39 *$ ); and (9) embedding of the madreporite in a cavity formed by one of the primary interradials (character $113 *$ ). The proposed character pertaining to the splitting of the muscle insertion odom into two different muscle insertions (odom 1 and odom2; Fau \& Villier, 2018) was not included in the matrix, but is likely to occur in at least three species of zoroasterids, as remains of the odom 2 is visible on the orals of Zoroaster fulgens, Zoroaster carinatus philippinensis and Zoroaster ophiactis (see Supporting Information, Fig. S4K). The head of the first ambulacral is higher than the head of other Forcipulatacea, but this character is homoplastic (character 11), as it is also found in Pedicellaster hypernotius, the sitchasterids Stichaster striatus and Smilasterias scalprifera and the asteriid Urasterias linckii.

\section{BRISINGIDA}

The Brisingida is a diverse clade of deep-sea forcipulatacean with more than a hundred described species (Mah \& Blake, 2012). They are also morphologically distinct from other Forcipulatacea. They have a small, circular disc, with six to 20 long and slender arms (Mah \& Blake, 2012). The Brisingida is currently divided into two families: the Brisingidae and the Freyellidae. In this study, only three species of Brisingida were included (Brisingaster robillardi, Odinella nutrix and Freyella elegans; Table 1), because specimens are scarce in collections. This renders the Brisingida under-represented in the sample and prevents us from inferring relationships within this clade.

The Brisingida is the second most-supported clade in our analysis with 13 synapomorphies, of which four are unambiguous. Some of these characters have already been described in the literature, such as the absence of straight pedicellariae (character $* 100$ ), the absence of actinal plates and the presence of only one marginal series (e.g. Fisher, 1928; Clark \& Downey, 1992). Brisingida possesses a distinctive oral frame, where orals, first ambulacrals and odontophores form a rigid oral ring (Figs 4A, B, 8C, D). This organization of the oral frame makes it difficult to separate the ossicles from one another and, therefore, lead to the idea that the ossicles are fused (Gale, 2011). However, we here confirm that the oral frame ossicles of brisingids imbricate to form a rigid oral ring (character *3) and do not fuse. Modification of the orals, first ambulacrals and odontophore to accommodate the oral ring were investigated in the three species present in the sample. The morphology of the orals, in particular, was found to be different from one species to another (see Supporting Information, Fig. S3K-P), suggesting that more anatomical work is needed to understand the morphology and the functionality of the oral ring of this group. Orals share important characters, like the abactinal position of the articulation iioa relative to the aciim (character $* 20$ ). This configuration is unique to the Brisingida (Fig. 6; see Supporting Information, Figs S3, S4). Odontophores and first ambulacrals of the Brisingida, on the contrary, have similar shapes, which allows the recognition of three synapomorphies based on the morphology of the odontophore (character *6) and the first ambulacrals (characters 11 and 12).

The Brisingida were scored with the adoral carina absent, because they do not fulfil the two criteria stated in Fau \& Villier (2018) for the recognition of an adoral carina: (1) at least the most proximal adambulacral is in contact with the most proximal adambulacral of the adjacent arm and (2) the presence of morphological differentiation of the adambulacral of the adoral carina Fig. 8A, B). If irregular contact can be observed between the most proximal adambulacrals of some arms, they show no differentiated morphology (Fig. 8C, D).

\section{CONVERGENT AND PLESIOMORPHIC CHARACTERS OF BRISINGIDA AND ZOROASTERIDAE}

The number of marginal rows in Zoroasteridae is still debated in the literature (Fau \& Villier, 2018). Authors describe either one or two rows of marginals in the Zoroasteridae (see discussion in: Fau \& Villier, 2018). For recognition of the marginal series, we follow the criteria discussed by Blake (1978, 1987), Blake \& Elliott (2003) and Blake \& Hagdorn (2003): to be interpreted as marginals, the series must arise immediately from the terminal, be in a marginal position on the body and be morphologically differentiated from the other series (i.e. from the carinals, abactinals and actinals). We here follow the conclusion of Fau \& Villier (2018) and recognize only one row of marginals in Zoroasteridae. For Brisingida, the recognition of marginal series is made difficult by the modified wall skeleton, as most of the plates are reduced proximally, or even absent distally (i.e. actinals, marginals, abactinals and carinals are reduced or disappeared). Clark \& Downey (1992: 462) described the marginals of Brisingida as follow: '[...] superomarginals not distinguishable; inferomarginals not corresponding one to one with adambulacrals (except in Brisinga hirsuta) [...]'. Thus, we only recognize a single row of marginal in Brisingida. However, there is no clear evidence regarding the homology of this unique row of marginals and whether it should be interpreted as inferomarginals or superomarginals. We, therefore, follow the dominant interpretation in the literature, that the unique marginal series in Zoroasteridae and Brisingida should be interpreted as inferomarginals (Blake \& Elliott, 2003; Blake \& Hagdorn, 2003; Mah, 
2007; Mah \& Blake, 2012; Blake \& Mah, 2014) and scored them accordingly in the matrix.

As expected, Zoroasteridae arises in a basal position in the tree (Fig. 2), and many previous phylogenetic studies supported this position (e.g. Blake, 1987; Gale, 1987; Mah, 2000; Mah \& Foltz, 2011a). However, Brisingida arise in a basal position too (Fig. 2), although several previous analyses supported them at a more derived position in the tree (Fig. 1; Mah, 2000; Mah \& Foltz, 2011a; Mah et al., 2015). The Zoroasteridae and the Brisingida share two important convergences: the presence of a crest separating the muscle insertions, padam and dadam, on the adambulacrals (Fig. 7O, $\mathrm{T}$, U; character 46) and the presence of only one row of marginals (character 62). The basal position of Brisingida could be explained by many plesiomorphic characters that they share with the Zoroasteridae and the outgroups. Noticeable plesiomorphic characters present in the Brisingida are the rough surface of the articulation iioa on the orals (Fig. 6F-H; character 18), the low compression of the ambulacral (Fig. $7 \mathrm{H}$, I, L; character 26), the absence of a collapse of the ambulacral head (character 30 ) and the presence of wings on the ambulacrals (Fig. 7H; character 34 ). Another important factor is the high proportion of non-applicable characters for the Brisingida and the Zoroasteridae. Indeed, because both of these group have only one row of marginals, the characters on the superomarginals were scored non-applicable. Actinal and carinals series cannot be recognized in the Brisingida and the corresponding characters were also scored non-applicable. Characters relating to the crossed pedicellariae were non-applicable for the Zoroasteridae and characters relating to straight pedicellariae were non-applicable for the Brisingida. In total, 25 characters were non-applicable for the Brisingida and 15 for Zoroasteridae. The combination of convergence between Brisingida and Zoroasteridae, the plesiomorphic characters exhibited by both clades and the high proportion of non-applicable characters are likely to be responsible for the placement at the basal polytomy of the Brisingida.

\section{CONVERGENCE IN MULTI-ARMED TAXA}

Sea stars generally have five arms, but it is not uncommon to find specimens with six arms or more. Such specimens are frequently found in fissiparous taxa (e.g. Stephanasterias albula and Coscinasterias tenuispina). In Forcipulatacea, multi-armed taxa (i.e. species that are always found with six or more arms) are present in every family, except for Zoroasteridae. In this study, nine species possessing more than five arms were included: the asteriids Coscinasterias tenuispina (MNHN-IE-2013-12866, 8 arms), Pycnopodia helianthoides (YPM 87689, 17 arms) and
Stephanasterias albula (YPM 876878, 6 arms), the heliasterids Heliaster cumingi (YPM No 87688, 38 arms), H. helianthus (UniFR-PL-2019-003, 33 arms) and Labidiaster annulatus (MNHN-IE-2013-12850, 42 arms) and the brisingids Brisingaster robillardi (MNHN-IE-2013-12874, 11 arms), Freyella elegans (MNHN-IE-2013-12862, 11 arms) and Odinella nutrix (MNHN-IE-2009-7198, 13 arms). Even though they are scattered across the tree (Fig. 2), the multiarmed species exhibit convergent characters on the ossicles of the oral frame (except for C. tenuispina and $S$. albula) and a reduced abactinal skeleton (except for $H$. cumingii and $H$. helianthus). These convergences are most likely functional, rather than the expression of homologous characters.

An enlarged number of arms is directly responsible for the modification of the shape of the oral frame. The mouth frame of multi-armed taxa is circular in shape and proportionally wider than in five-armed taxa (Fig. 8C, D). Convergent characters are preferentially shared between Heliaster and L. annulatus due to their close position in the tree (Fig. 2) and can be shared with Brisingida or with P. helianthoides (Table 3). The only character present in all the four taxa is the absence of the articulation doda on oral ossicles (Fig. 6B, E, F; Table 3; see Supporting Information, Figs S3, S4), contrary to other Forcipulatacea (exception for Diplasterias brucei and Notasterias armata), where both the articulation poda and doda are present on the orals. That means that the odontophores lie distally only on the first ambulacrals (articulation poda; see Supporting Information, Fig. S2D, L) and not on both the oral and ambulacral like in the five-armed taxa (Figs 5,6). The odontophore of $P$. helianthoides exhibits the typical butterfly shape of Forcipulatacea (Fig. 4), but the odontophore of the other multi-armed taxa have a different shape. The odontophore of L. annulatus, Heliaster and Brisingida possesses a lateral notch separating the articulations poda and $\operatorname{dod} a$, and if the shape of the odontophore of Heliaster is singular (see Supporting Information, Fig. S1), the odontophore of L. annulatus and the Brisingida have a similar shape (Fig. 4E, H). Concerning the other ossicle of the oral frame, the Brisingida possesses singular orals and first ambulacrals that are highly modified due to their rigid oral frame, the orals of $P$. helianthoides are similar to the orals of other Asteriidae and the orals of L. annulatus are similar to Heliaster (see Supporting Information, Fig. S4E-H). The first ambulacral of Heliaster, L. annulatus and P. helianthoides are much alike (Fig. 5E, F). They are extremely long, short in height (characters 11 and 12; see Supporting Information, Fig. S2) and the articulation doda is placed on the shaft or the head of the distal process of the ossicle, which is a higher position than in any other Forcipulatacea, where it usually stands at the 
Table 3. List of convergent characters in multi-armed taxa (in grey cells). See Appendix 1 for full character description, and File S2 for character matrix

\begin{tabular}{|c|c|c|c|c|}
\hline Character / taxa & P. helianthoides & L. annulatus & Heliaster & Brisingida \\
\hline 5. Odontophore, butterfly shape & (1) present & (0) absent & (0) absent & (0) absent \\
\hline $\begin{array}{l}\text { 8. Odontophore, articulation } \\
\text { areas poda and doda }\end{array}$ & $\begin{array}{l}\text { (1) separated, but on } \\
\text { the same surface }\end{array}$ & $\begin{array}{l}\text { (2) physically } \\
\text { separated by a } \\
\text { lateral notch }\end{array}$ & $\begin{array}{l}\text { (2) physically } \\
\text { separated by a } \\
\text { lateral notch }\end{array}$ & $\begin{array}{l}\text { (2) physically } \\
\text { separated by a } \\
\text { lateral notch }\end{array}$ \\
\hline $\begin{array}{l}\text { 9. Articulation area doda of the } \\
\text { odontophore linked to: }\end{array}$ & $\begin{array}{l}\text { (2) first ambulacrals } \\
\text { only }\end{array}$ & $\begin{array}{l}\text { (2) first ambulacrals } \\
\text { only }\end{array}$ & $\begin{array}{l}\text { (2) first } \\
\text { ambulacrals } \\
\text { only }\end{array}$ & $\begin{array}{l}\text { (2) first } \\
\text { ambulacrals only }\end{array}$ \\
\hline $\begin{array}{l}\text { 11. First ambulacral, ratio } \\
\text { between the length and the } \\
\text { height of the distal process }\end{array}$ & $(2)>1.7$ & $(2)>1.7$ & $(2)>1.7$ & $\begin{array}{l}\text { (1) between } 0.9 \\
\text { and } 1.7\end{array}$ \\
\hline $\begin{array}{l}\text { 12.First ambulacral, ratio } \\
\text { between the length and the } \\
\text { height of the proximal process }\end{array}$ & (3) $>6$ & (3) $>6$ & (3) $>6$ & (2) between 4 and 6 \\
\hline $\begin{array}{l}\text { 14. First ambulacral, position } \\
\text { of the articulation with the } \\
\text { odontophore doda }\end{array}$ & $\begin{array}{l}\text { (1) on the shaft/head } \\
\text { of the distal process }\end{array}$ & $\begin{array}{l}\text { (1) on the shaft/head } \\
\text { of the distal process }\end{array}$ & $\begin{array}{l}\text { (1) on the } \\
\text { shaft/head of } \\
\text { the distal } \\
\text { process }\end{array}$ & $\begin{array}{l}\text { (0) on the base of } \\
\text { distal process }\end{array}$ \\
\hline 54. Actinals & $\begin{array}{l}\text { (0) absent or reduced, } \\
\text { loose in the dermal } \\
\text { tissues }\end{array}$ & $\begin{array}{l}\text { (0) absent or reduced, } \\
\text { loose in the dermal } \\
\text { tissues }\end{array}$ & (1) present & $\begin{array}{l}\text { (0) absent or re- } \\
\text { duced, loose in } \\
\text { the dermal tis- } \\
\text { sues }\end{array}$ \\
\hline 85. Carinals & (0) absent & (1) present & (1) present & (0) absent \\
\hline
\end{tabular}

base of the distal process (see Supporting Information, Fig. S2D, L).

The last convergence we observe is the reduction of the abactinal skeleton. The abactinal skeleton can be considered to be reduced when the surface the plates cover (actinals, marginals, abactinals and carinals) is less than the surface of bare skin. The reduction of the skeleton affects each taxon differently, even each plate series. It is observable in the brisingids, $P$. helianthoides and L. annulatus, but also in two other multi-armed taxa not included in this study, Coronaster pauciporis (Jangoux, 1984) and Plazaster borealis (Fisher, 1941). On the contrary, the abactinal skeleton of the genus Heliaster is well developed along the entire length of the arms. In the phylogenetic analysis of Mah (2000), the genera Coronaster, Labidiaster and Plazaster were found to form the sister-clade of the Brisingida. Molecular analysis, on the contrary, supports Coronaster and Plazaster as member of Asteriidae and Labidiaster as the sistergroup to Heliaster (Mah \& Foltz, 2011a), suggesting that convergent characters are due to functional constraint rather than express phylogenetic information. Convergence in the reduction of the abactinal skeleton can be expressed and classified in three different areas. First, the carinals tend to distally disappear in L. annulatus and Coronaster pauciporis, which is also observable in the five-armed
Urasterias linckii. The skeleton is highly modified/ reduced in the Brisingida and $P$. helianthoides, and the carinal series is, therefore, not recognizable proximally. Second, the inferomarginals do not overlap each other in L. annulatus, Plazaster borealis (Fisher, 1941) and in the Brisingida. The superomarginals are separated from each other by intercalary ossicles in L. annulatus, Plazaster borealis (Fisher, 1941), Coronaster pauciporis (Jangoux, 1984) and Urasterias linckii (Fig. 9B-D). Third, the actinals are absent in all the multi-arm taxa, except Heliaster. Reduction of the abactinal skeleton is frequent in multi-armed forcipulataceans, but not in a uniform way (Fig. 9A-D).

\section{CONCLUSIONS}

Because homoplasy is widespread among forcipulataceans, it is important to have a comprehensive view of the morphology of the group. We present here the largest morphological-based character matrix for the group, built on the comprehensive comparative anatomical analysis of 29 taxa. The anatomy of the ossicles permits us to define several new characters and to discuss the homology of commonly used characters (i.e. wreath organs, adoral carina). A comprehensive knowledge of ossicle anatomy is essential for the 
description of new extant species but, more importantly, to assess the phylogenetic position of many fossil taxa.

The Asteriidae, Brisingida, Stichasteridae and Zoroasteridae are recovered as monophyletic. Further investigation into the anatomy of other forcipulatacean species should help to resolve the remaining uncertainties, such as the internal structure of various clades. The internal relationship among Asteriidae remains poorly supported. Further investigation of the body-wall structure in additional species may be useful to better understand the complicated functional and ontogenetic patterns observed in the Asteriidae. Inclusion of fossil forms may also help to identify plesiomorphic characters, to date diversification patterns and to test their potential link with the paleogeographic history of the Asteriidae.

\section{ACKNOWLEDGMENTS}

We are grateful to Marc Eléaume (MNHN) and Eric Lazo-Wasem (YPM) for the loan of the specimens used in this study, and to Cyndie Dupoux (MNHN), Anouchka Sato (MNHN), Pierre Lozouet (MNHN) and Lourdes Rojas (YPM) for their assistance in the management of the borrowed specimens. We thank Christopher Mah (National Museum of Natural History) and Andy Gale (University of Portsmouth) for discussion and insight into asteroid taxonomy, and the two anonymous reviewers for their comments. We thank Christoph Neururer (University of Fribourg) for assistance with SEM imaging. Finally, we are thankful to Walter Joyce (University of Fribourg) for his support and for reading an earlier draft of this manuscript.

\section{REFERENCES}

Blake D. 1972. Sea star Platasterias: ossicle morphology and taxonomic position. Science 176: 306-307.

Blake D. 1973. Ossicle morphology of some recent asteroids and description of some West American fossil asteroids. University of California Publications in Geological Sciences 104: $1-59$.

Blake DB. 1987. A classification and phylogeny of postPalaeozoic sea stars (Asteroidea: Echinodermata). Journal of Natural History 21: 481-528.

Blake DB, Elliott DR. 2003. Ossicular homologies, systematics, and phylogenetic implications of certain North American Carboniferous asteroids (Echinodermata). Journal of Paleontology 77: 476-489.

Blake DB, Hagdorn H. 2003. The Asteroidea (Echinodermata) of the Muschelkalk (Middle Triassic of Germany). Paläontologische Zeitschrift 77: 23-58.
Blake DB, Mah CL. 2014. Comments on 'The phylogeny of post-Palaeozoic Asteroidea (Neoasteroidea, Echinodermata)' by AS Gale and perspectives on the systematics of the Asteroidea. Zootaxa 3779: 177-194.

Chia F-S, Amerongen H. 1975. On the prey-catching pedicellariae of a starfish, Stylasterias forreri (de Loriol). Canadian Journal of Zoology 53: 748-755.

Clark HL. 1907. The stafish of the genus Heliaster. Bulletin of the Museum of Comparative Zoology 51: 25-76.

Clark AM, Downey ME. 1992. Starfishes of the Atlantic. London: Chapman \& Hall.

Cuénot L. 1887. Contribution à l'étude anatomique des Astérides. Poitiers: Oudin.

Downey ME. 1970. Zorocallida, new order, and Doraster constellatus, new genus and species, with notes on the Zoroasteridae (Echinodermata; Asteroidea). Smithsonian Contributions to Zoology 64: 1-18.

Emson RH, Young CM. 1994. Feeding mechanism of the brisingid starfish Novodinia antillensis. Marine Biology 118: 433-442.

Fau M, Villier L. 2018. Post-metamorphic ontogeny of Zoroaster fulgens Thomson, 1873 (Asteroidea, Forcipulatacea). Journal of Anatomy 233: 644-665.

Feuda R, Smith AB. 2015. Phylogenetic signal dissection identifies the root of starfishes. PLoS One 10: e0123331.

Fisher WK. 1911. Asteroidea of the North Pacific and adjacent waters, pt. 1. Phanerozonia and Spinulosida. Bulletin of the US National Museum 76: 1-122.

Fisher WK. 1928. Asteroidea of the North Pacific and adjacent waters, pt. 2: Forcipulata (Part). Bulletin of the US National Museum 76: 1-245.

Fisher WK. 1930. Asteroidea of the North Pacific and adjacent waters, pt. 3: Forcipulatida (concluded). Bulletin of the US National Museum 76: 1-356.

Fisher WK. 1941. A new genus of sea stars Plazaster from Japan, with a note on the genus Parasterina. Proceedings of the United States National Museum 90: 447-456.

Foltz DW, Bolton MT, Kelley SP, Kelley BD, Nguyen AT. 2007. Combined mitochondrial and nuclear sequences support the monophyly of forcipulatacean sea stars. Molecular Phylogenetics and Evolution 43: 627-634.

Gale AS. 1987. Phylogeny and classification of the Asteroidea (Echinodermata). Zoological Journal of the Linnean Society 89: 107-132.

Gale AS. 2011. The phylogeny of post-Palaeozoic Asteroidea (Neoasteroidea, Echinodermata). Special Papers in Palaeontology 85: 1-112.

Gale A, Villier L. 2013. Mass mortality of an asteriid starfish (Forcipulatida, Asteroidea, Echinodermata) from the late Maastrichtian (Late Cretaceous) of Morocco. Palaeontology 56: $577-588$.

Jangoux M. 1984. Les astérides littoraux de NouvelleCalédonie. Bulletin du Muséum National d'Histoire Naturelle. Section A, Zoologie, Biologie et Écologie Animales 6: $279-293$.

Janies D. 2001. Phylogenetic relationships of extant echinoderm classes. Canadian Journal of Zoology 79: 1232-1250. 
Janies D, Mooi R. 1998. Xyloplax is an asteroid. In: Carnevalii C, Bonsoro F, eds. Echinoderms research. Rotterdam: Balkema, 311-316.

Janies DA, Voight JR, Daly M. 2011. Echinoderm phylogeny including Xyloplax, a progenetic asteroid. Systematic Biology 60: $420-438$

Kroh A, Smith AB. 2010. The phylogeny and classification of post-Palaeozoic echinoids. Journal of Systematic Palaeontology 8: 147-212.

Lambert A, De Vos L, Jangoux M. 1984. Functional morphology of the pedicellariae of the asteroid Marthasterias glacialis (Echinodermata). Zoomorphology 104: 122-130.

Lawrence J, Komatsu M. 1990. Mode of arm development in multi-armed species of asteroids. In: DeRidder C, Dubois R, Lahaye M-C, Jangoux M, eds. Echinoderm research. Rotterdam: Balkema, 269-275.

Linchangco GV, Foltz DW, Reid R, Williams J, Nodzak C, Kerr AM, Miller AK, Hunter R, Wilson NG, Nielsen WJ, Mah CL, Rouse GW, Wray GA, Janies DA. 2017. The phylogeny of extant starfish (Asteroidea: Echinodermata) including Xyloplax, based on comparative transcriptomics. Molecular Phylogenetics and Evolution 115: 161-170.

Maddison WP, Maddison DR. 2018. Mesquite: a modular system for evolutionary analysis. Version 3.51. Available at: http://www.mesquiteproject.org.

Mah CL. 2019. World Asteroidea database. Zoroasteridae Sladen, 1889. Accessed through: World Register of Marine Species at. Available at: http://www.marinespecies.org/aphia. php?p=taxdetails\&id=123125 (accessed on 17 May 2019).

Mah CL. 2000. Preliminary phylogeny of the forcipulatacean Asteroidea. American Zoologist 40: 375-381.

Mah C. 2007. Phylogeny of the Zoroasteridae (Zorocallina; Forcipulatida): evolutionary events in deep-sea Asteroidea displaying Palaeozoic features. Zoological Journal of the Linnean Society 150: 177-210.

Mah CL, Blake DB. 2012. Global diversity and phylogeny of the Asteroidea (Echinodermata). PLoS One 7: e35644.

Mah C, Foltz D. 2011a. Molecular phylogeny of the Forcipulatacea (Asteroidea: Echinodermata): systematics and biogeography. Zoological Journal of the Linnean Society 162: 646-660.

Mah C, Foltz D. 2011b. Molecular phylogeny of the Valvatacea (Asteroidea: Echinodermata). Zoological Journal of the Linnean Society 161: 769-788.

Mah C, Nizinski M, Lundsten L. 2010. Phylogenetic revision of the Hippasterinae (Goniasteridae; Asteroidea): systematics of deep sea corallivores, including one new genus and three new species. Zoological Journal of the Linnean Society 160: 266-301.
Mah C, Linse K, Copley J, Marsh L, Rogers A, Clague D, Foltz D. 2015. Description of a new family, new genus, and two new species of deep-sea Forcipulatacea (Asteroidea), including the first known sea star from hydrothermal vent habitats. Zoological Journal of the Linnean Society 174: 93-113.

Mortensen T. 1927. Handbook of the echinoderms of the British Isles. London: Oxford University Press.

Perrier E. 1884. Mémoire sur les étoiles de mer recueilliés dans la mer des Antilles et le golfe du Mexique: durant les expéditions de dragace faites sous la direction de M. Alexandre Agassiz. Archive du Muséum national d'histoire naturelle, Paris 6: 127-276.

Perrier E. 1885. Première note préliminaire sur les Echinodermes. Annales des Sciences Naturelles, Zoologie 22: 1-72.

Perrier E. 1894. Échinodermes. Stellérides. Expéditions scientifiques du Travailleur et du Talisman pendant les années 1880, 1881, 1883. Paris: G. Masson. 1-431.

Schwertmann L, Focke O, Dirks J-H. 2019. Morphology, shape variation and movement of skeletal elements in starfish (Asterias rubens). Journal of Anatomy 234: 656-667.

Sladen WP. 1889. Report on the Asteroidea. Report on the scientific results of the voyage of H.M.S. challenger during the years 1873-76. Zoology 30: 1-935.

Smith AB. 1980. Stereom microstructure of the echinoid test. Special Paper in Paleontology 25: 1-324.

Spencer W, Wright C. 1966. Asterozoans. In: Moore RC, ed. Treatise on invertebrate paleontology, Part U, Echinodermata 3, Vol. 1. Lawrence: University of Kansas Press, 4-107.

Swofford DL. 2002. PAUP*: phylogenetic analysis using parsimony (*and other methods). Version 4. Sunderland: Sinauer Associates.

Thomson CW. 1873. The depths of the sea. London: Macmillan. Thuy B, Stöhr S. 2016. A new morphological phylogeny of the Ophiuroidea (Echinodermata) accords with molecular evidence and renders microfossils accessible for cladistics. PLoS One 11: e0156140.

Turner RL, Dearborn JH. 1972. Skeletal morphology of the mud star, Ctenodiscus crispatus (Echinodermata: Asteroidea). Journal of Morphology 138: 239-262.

Viguier C. 1878. Classification des Stellérides. Comptes Rendus de l'Académie des Sciences, Paris 84: 681-683.

Villier L, Blake DB, Jagt JWM, Kutscher M. 2004. A preliminary phylogeny of the Pterasteridae (Echinodermata, Asteroidea) and the first fossil record: Late Cretaceous of Germany and Belgium. Paläontologische Zeitschrift 78: 281-299.

Wada H, Komatsu M, Satoh N. 1996. Mitochondrial rDNA phylogeny of the Asteroidea suggests the primitiveness of the Paxillosida. Molecular Phylogenetics and Evolution 6: 97-106. 


\section{SUPPORTING INFORMATION}

Additional Supporting Information may be found in the online version of this article at the publisher's web-site.

File S1. List specimens examined.

File S2. Character matrix.

Figure S1. Scanning electron microscopy (SEM) images of odontophores.

Figure S2. Scanning electron microscopy (SEM) images of first ambulacral ossicles.

Figure S3. Scanning electron microscopy (SEM) images of oral ossicles.

Figure S4. Scanning electron microscopy (SEM) images of oral ossicles.

Figure S5. Scanning electron microscopy (SEM) images of ambulacral ossicles.

Figure S6. Scanning electron microscopy (SEM) images of ambulacral ossicles.

Figure S7. Oral frame of Odinella nutrix (MNHN-IE-2009-7198) and Diplasterias brucei (MNHN-IE-2013-16032) in actinal view. Scanning electron microscopy (SEM) images of the adambulacrals of the adoral carina of Myxoderma sp. (MNHN-IE-2013-16033) in actinal view, and of isolated adambulacrals ossicles.

Figure S8. Wall skeleton arrangement along the arms of forcipulatids.

Figure S9. Scanning electron microscopy (SEM) images of inferomarginals and superomarginals.

Figure S10. Scanning electron microscopy (SEM) images of spines, straight forcipulate pedicellariae, and crossed pedicellariae.

\section{APPENDIX 1 \\ CHARACTER DESCRIPTIONS}

\section{GENERAL MORPHOLOGY (CHAR. 1-3)}

Comments on general morphological characters: The number of tube feet rows (i.e. four or two rows per arm) was used historically to characterized Forcipulatida and was used in phylogenetic analysis (Mah, 2000, 2007; Blake and Hagdorn, 2003). However, this character is homoplastic in all analysis. For this reason, this character was not used in this analysis.

1. Number of arms: (0) 5 arms; (1) 6 to 16 arms; (2) 17 to 50 arms.

Modified from (Gale, 2011).

Comments: The number of arms was used by Gale (2011) as a phylogenetic character, with three states: (0) $5 \mathrm{arms}$, (1) 6 to $10 \mathrm{arms}$ and (2) more than $10 \mathrm{arms}$. We rather choose to score the character following the interpretation of Lawrence \& Komatsu (1990), because it allows separating previously recognized clades, such as the Brisingida, which would be coded as Labidiaster annulatus, Heliaster and Pycnopodia helianthoides with the scoring used by Gale (2011).

2. Position of the peristome: (0) actinostome; (1) deeply sunken actinostome.

Modified from Mah (2007).
Comments: According to our observations, zoroasterids tends to have a longer adoral carina (composed of more than three adambulacrals) in the adult stage (Fau \& Villier, 2018) than other forcipulatids, causing bending of the adambulacral series toward the peristome and the development of an actinostome. This character was used for taxonomic purposes by Downey (1970) and Clark \& Downey (1992:.402 'actinostome deeply sunken to form a peristomial cavity') and as a phylogenetic character by Mah (2007).

3. Partial fusion of the oral frame ossicles (orals, first ambulacrals and odontophores) forming a rigid ring: (0) absent; (1) present.

Comments: Gale (2011) used two characters to express the partial fusion of the oral frame, the character number 86 'mouth frame ring like, inflexible' and the character number 98 'odontophore fused with oral ossicles', which are both cited as synapomorphies of the Brisingida. In the present study, we found that odontophores of the Brisingida, although tightly attached to the orals, are not truly fused with them. Orals and odontophores can be separated by leaving the ossicles long enough in bleach. The orals and first ambulacrals of Brisingida are also highly modified and create a rigid, inflexible oral ring (Fig. 4A, B). Mah (2007) defined the character 'oral ring fused. 0, not fused; 1, fused' (character 59, Appendix 1), and scored the oral ring of Zoroasteridae as fused. In this study, all zoroasterids are scored as (0) partial fusion of the oral ring absent. Fau \& Villier (2018) demonstrated that the oral ossicles of Zoroaster fulgens are strongly bond to each other, but they are neither fused with 
each other, nor with first ambulacrals or odontophores. In addition, the oral frame of Zoroasteridae typically has a pentagonal shape, and not a ring shape.

\section{ORAL FRAME (CHAR. 4-25)}

General comments on the odontophore: The first matrix proposed for the Forcipulatacea by Mah (2000) considers a single character for the odontophore, his character number 5: 'pillar on odontophore: (0) absent; (1) present'. However, no definition of the pillar was available in the publication, making it impossible to reuse the character. The keel, defined by Gale (2011), was not included in this character matrix because it is absent in the Forcipulatacea.

4. Odontophore, crater: (0) absent; (1) present.

Comments: The crater is defined as a small depression on the abactinal surface of the ossicle (Supporting Information, Fig. S1), generally placed at the top of a bump, on which a circular articulation and a muscle insertion allow the attachment of the internal interradial actinals (iia).

5. Odontophore, butterfly shape: (0) absent; (1) present.

6. Odontophore: (0) longer than wide; (1) wider than long.

7. Odontophore: (0) distal part approximately the same size or wider than the proximal part; (1) proximal part wider than the distal part.

Comments for characters 5, 6, and 7: These characters describe the shape of the odontophores, whereas characters 8 and 9 describe the relationship between the odontophore and the rest of the oral frame. Gale (2011) used one character to express the shape of the odontophore, the character number 93 . The state (2) odontophore 'rhomboidal-trapezoidal' was found to be a synapomorphy of the Forcipulatida. We prefer to describe the typical shape of the odontophore of the Forcipulatida as butterfly shape (Supporting Information, Fig. S1A-F), and to use other characters to express shape variations among taxa. For example, Leptasterias compta, Zoroaster fulgens and Neomorphaster forcipatus (Supporting Information, Fig. S1A-F) show a typical butterfly shape, whereas the odontophore of Brisingaster robillardi, Heliaster cumingi and Dactylosaster cylindricus exhibit other shapes, and are, therefore, coded absent (0) for character 5 (Supporting Information, Fig. S1G-L). Character 6 was coded wider than long (1) for all the taxa, except Brisingida (Supporting Information,
Fig. S1G). For the odontophores that show a rather square shape, like Heliaster helianthus and Heliaster cumingi (Supporting Information, Fig. S1H, K), we chose to code them (1). The width of the odontophore may vary from the proximal to the distal part of the ossicle. Character 7 summarizes this variation (e.g. see the red arrows in Supporting Information, Fig. S1A, G).

8. Odontophore, articulation areas poda and doda: (0) fused; (1) separated, but on the same surface; (2) physically separated by a lateral notch.

Comments: The fused articulations poda and doda of Zoroaster fulgens (Supporting Information, Fig. S1E) illustrate state (0). State (1) is visible in Leptasterias compta and Neomorphaster forcipatus (Supporting Information, Fig. S1D, F), and state (2) is visible in Brisingaster robbillardi, Heliaster cumingi and Dactylosaster cylindricus (Supporting Information, Fig. S1J-L). The fusion of the articulations poda and doda is a synapomorohy of the Zoroasteridae.

9. Articulation area doda of the odontophore linked to: (0) orals only; (1) both orals and first ambulacrals; (2) first ambulacrals only.

Comments: Depending on the structure of the oral frame, the odontophore can articulate with the orals only, or both the orals and the first ambulacrals. This can be determined by checking if the articulation doda is present or absent on the orals and/or on the abactinal side of the first ambulacrals (see Supporting Information, Figs S2, S3, S4). This character was modified from Gale (2011) to include the state where the articulation doda lays on both the orals and first ambulacrals (see Leptasterias compta and Stichaster striatus in Supporting Information, Figs S2B, H, S3A, $\mathrm{S} 4 \mathrm{C})$.

10. First ambulacral, furrow: (0) absent; (1) present.

Comments: In most Forcipulatacea, a furrow is present on orals and ambulacrals ossicles right under the riom on the orals and under the actam on the ambulacrals (Fau \& Villier, 2018). Even if this character seems to appear late in the ontogeny of Zoroaster fulgens (Fau \& Villier, 2018), it is present in small stichasterids and asteriids. The furrow is present in all studied Stichasteridae, Zoroasteridae and Asteriidae (Supporting Information, Fig. S2A, C, E-G, M), and absent in other taxa (Supporting Information, Fig. $\mathrm{S} 2 \mathrm{I}, \mathrm{K}, \mathrm{N}, \mathrm{O}$ ), except for Odinella nutrix, which is the only species of Brisingida to have a furrow on the first ambulacrals. 
11. First ambulacral, ratio between the length and the height of the distal process: $(0)<0.9$; (1) between 0.9 and $1.7 ;(2)>1.7$.

12. First ambulacral, ratio between the length and the height of the proximal process: $(0)<2$; (1) between 2 and 4 ; (2) between 4 and $6 ;(3)>6$.

13. First ambulacral, ratio between the height of the proximal and distal process: $(0)<2 ;(1)>2$.

Comments for characters 11, 12 and 13: These characters describe the shape of the first ambulacrals. Gale (2011) used two characters to express shape variation of the first ambulacrals (also called circumoral ossicles): character 107: 'circumoral ossicles higher than long (0), longer than high (1)' and character 111: 'circumoral heads short (=1-2 adjacent ambulacrals) (0), elongated (=3-6 ambulacrals) (1)'. However, these two characters fail to discriminate the first ambulacrals with a wide head (Supporting Information, Fig. S2A, B, I, J) or a wide head (Supporting Information, Fig. S2C, $\mathrm{D}, \mathrm{K}$, ), which are the most obvious differences among the first ambulacrals of Forcipulatacea. We modified character 107 of Gale (2011) to accommodate more morphological variation. Coding from ratio between ossicle dimensions makes the scoring of the character matrix more easily reproducible.

First ambulacrals are divided into three parts: the head (from the teeth to the actam), the distal process, and the proximal process. Three measurements were taken: (1) the length of the head, taken along the first row of teeth; (2) the proximal process height, from the top of the row of teeth to the proximalmost part of the articulation procoa; and (3) the distal process height, from the top of the row of teeth to the end of the furrow or to the tip of the distal process when the furrow is absent (red dashed lines in Supporting Information, Fig. S2). The limits between character states were defined after plotting the value distribution and checking for distinct morphological groups.

It is worth noticing that Pycnopodia helianthoides and Heliaster helianthus have similar first ambulacrals with short distal processes and long heads that give the first ambulacrals a typical triangular shape (Supporting Information, Fig. S2C, D, K, L). This is an example of the many morphological convergences between multi-armed forcipulatacean sea stars (i.e. Brisingida, Heliaster, Labidiaster annulatus and Pycnopodia helianthoides).

14. First ambulacral, position of the articulation with the odontophore doda: (0) on the base of distal process; (1) on the shaft/head of the distal process.

Comments: The position of the articulation doda varies in either being on the shaft or on the head of the first ambulacrals (Supporting Information, Fig. S2D, H, J, L). However, the presence of the articulation doda on the shaft seems to be convergent among the species that have more than 30 arms (i.e. Heliaster, Labidiaster annulatus and Pycnopodia helianthoides; Supporting Information, Fig. S2B, D, H, L), just as for characters 11, 12 and 13 (see above).

15. First ambulacral, distal process: (0) distal process projecting distally and forming an angle with the head; (1) distal process and distal side of the head on the same line.

16. First ambulacral, orientation of the procoa and dicoa: (0) nearly parallel; (1) not parallel.

17. First ambulacral, angle between the proximal process and the proximal edge of the head: (0) acute angle; (1) right or obtuse angle.

Comments for characters 15, 16 and 17: The shape of the first ambulacrals is described using measurements. The distal process can be orientated distally from the head (see angles in yellow; Supporting Information, Fig. S2M, O, P; Gale, 2011), but in most species, the distal process and the head are aligned. Only the two outgroups did not present nearly parallel procoa and dicoa articulations (Supporting Information, Fig. S2O, P). The proximal angle of the head (character 17; see angles in blue; Supporting Information, Fig. S2B, L, P) can also vary, most of the species show a rather acute angle (Supporting Information, Fig. S2B, L), whereas some have an obtuse angle (Supporting Information, Fig. S2P).

18. Orals, surface of the articulation iioa: (0) made of smooth stereom; (1) surface not smooth, sometimes made of imperforate stereom.

19. Orals, teeth on the interoral articulation iioa: (0) absent; (1) present.

Comments for characters 18 and 19: In all the Forcipulatacea, except the Zoroasteridae and the Brisingida, the articulation iioa is made of a smooth surface of labyrinthic or reticulate stereom (Smith, 1980) (Supporting Information, Figs S3, S4). The Brisingida and the Zoroasteridae develop an especially complex surface (Supporting Information, Figs S3K, $\mathrm{M}, \mathrm{O}, \mathrm{S} 4 \mathrm{~K}$ ) that reinforces the rigidity of the oral frame (Fau \& Villier, 2018). However, in the Zoroasteridae, the surface of the iioa is made of well-defined teeth, formed by galleried stereom, that is not considered homologous with the structure of the iioa present in the Brisingida (Smith, 1980; Fau \& Villier, 2018).

20. Orals, position of the articulation iioa compare to the muscle insertion aciim: (0) iioa in actinal position; (1) iioa in abactinal position; (2) aciim divided in two around the iioa. 
Comments: The positions of the muscle insertions and articulations vary in the Forcipulatacea. The character describes the different relations observed between the articulation iioa and the muscle insertion aciim. In most taxa, the iioa is in actinal position compared to the aciim (Supporting Information, Figs S3A, C, E-G, I, S4A, C, I, K, N). In the Brisingida, it is the aciim that is in actinal position (Supporting Information, Fig. $\mathrm{S} 3 \mathrm{~K}, \mathrm{M}, \mathrm{O}$ ), and in the Heliasteridae the aciim is more developed than in other taxa, occupying the entire width of the body all around the iioa (Supporting Information, Fig. S4E, G).

21. Orals, proximal angle of the body: (0) smooth angle, more or less $90^{\circ}$; (1) sharp angle, less than $70^{\circ}$.

Comments: The proximal angle of the body (pab in Supporting Information, Fig. S4) provides an objective and simple way to characterize the shape of the body. In most forcipulatacean, the proximal angle of the body is approximately $90^{\circ}$ (Supporting Information, Fig. S4A), but in the Heliasteridae and in Pedicellaster hypernotius this angle is sharper (Supporting Information, Fig. S4E-J).

22. Orals, position of the rvg: (0) in proximal position compare to the abiim; (1) in abactinal position compare to the abiim.

23. Orals, rvg: (0) shallow, almost invisible; (1) well defined.

Comments for characters 22 and 23: In all the Forcipulatacea, the rvg is proximal to the muscle insertion abiim, whereas it is in abactinal position to the abiim in the outgroups (Supporting Information, Fig. S4N). The rvg is always directly abactinal to the muscle insertion riom. However, in some taxa, such as Pisaster ochraceus and Asterias forbesi (Supporting Information, Fig. S3E, F), rvg is shallow compared to the well-marked groove visible in other taxa (e.g. Supporting Information, Fig. S3G). Character 23 is similar to character 117 in the character list of Gale (2011) 'groove for radial vessel (rvg) on inner face of oral apophyse short (0), elongated (1)'.

24. Orals, contact with the second ambulacral along the distal edge: (0) absent; (1) present.

Comments: This contact is present in the Heliasteridae, Stichasteridae, and Asteridae along the distal edge of the plateau, but is absent in the Zoroasteridae and the Brisingida.
25. Orals, number of enlarged spine bases (round pustules or keyhole pustules): (0) 1 to 3; (1) 4 and more.

Comment: The spines can be counted in the specimens before dissection, but observation of the ossicles through SEM images allows to differentiate pustules from bumps and, therefore, to determine the homology of the spines. Spines attached to bumps are generally smaller compared to spines attached to the pustules (for abbreviations see Table 2; Supporting Information, Figs S3, 4).

\section{AMBULACRAL GROOVE (CHAR. 26-53)}

General comments on the ambulacrals: SEM images were taken of ambulacral ossicles in actinal, abactinal, proximal and distal views (Supporting Information, Figs S5, S6). Three measurements were taken (as described in: Fau \& Villier, 2018): the height, from the base of teeth to the actinal point of the base; the length of the head taken at the base of the teeth; and the shortest length of the central constriction under the actam (Supporting Information, Fig. S5H).

26. Ambulacral, ratio between the length and the height of the ossicle: (0) low (>4.5); (1) average $(4.5<\mathrm{X}<9)$; (2) high $(>9)$.

Comments: This character is relatively similar to character 70 of Mah (2007) and character 70 of Gale (2011). The length/height ratio represents the compression of the ambulacrals. Typically, the Forcipulatida is described in the literature as having compressed ambulacrals (Clark and Downey, 1992). Ratios were used to differentiate morphological groups. Ambulacrals of Brisingida are not compressed and generally have a large head (Supporting Information, Fig. S5S-Y). Most taxa examined have an average ratio between 4.5 and 9 , but some, such as Pisaster ochraceus and Stephanasterias albula, have highly compressed ambulacrals (Supporting Information, Fig. S5D, J-K).

27. Ambulacral, ratio between the teeth length and the minimal body length: $(0)<1$; (1) $1=<\mathrm{X}<2$, rod shape; (2) $1=<\mathrm{X}<2$, hourglass shape.

Comments: This ratio expresses the shape of the ambulacrals, in particular an hourglass shape versus a straight shape. Only Labidiaster annalutus has a shorter teeth length than its body length (Supporting Information, Fig. S6E-G). The hourglass shape is 
present in the outgroup Plutonaster bifrons and in the Brisingida (Supporting Information, Figs S5S-Y, S6N, O). Both Labidiaster annalutus and Pedicellaster hypernotius have an elongated head and superficially present an hourglass shape (Supporting Information, Fig. S6E-J), but they were not coded as such, because the teeth are not present along the entire head, and only the teeth length is considered for this character.

28. Ambulacral, abactinal bending of the ambulacral ossicles: (0) absent, the abactinal edge is rather straight; (1) abactinal edge slightly depressed in its mid part; (2) strongly arched.

Comments: The abactinal edge of the ambulacrals can be straight (Supporting Information, Fig. S6G, $\mathrm{J}, \mathrm{M}, \mathrm{Q}$ ) or rather concave, as in most Forcipulatacea (Supporting Information, Figs S5, S6). Asteriids have strongly bent ambulacral ossicles (Supporting Information, Fig. S5C, F, G, J, K). The concavity of the abactinal side is less pronounced in the ambulacral ossicles of other Forcipulatacea, such as Stichaster striatus, Neomorphaster forcipatus (Supporting Information, Fig. S5N-R) and Heliaster cumingi (Supporting Information, Fig. S6C, D).

29. Ambulacral, extension on the head of the lim muscle insertion: (0) lim short (less than $40 \%$ of the ossicle height); (1) lim long, more than $40 \%$ of the ossicle height and finishing under the actam.

Comments: The lim can be short (Supporting Information, Figs S5I, M, N, Q, R, T-Y, S6C, D, M) or long (Supporting Information, Figs S5C, F, G, J, K, Q, $\mathrm{R}, \mathrm{S} 6 \mathrm{E}-\mathrm{G})$. In case of doubt, the lim was considered short if it stops before the actam, and long if it exceeds the actam.

30. Ambulacral, proximal tilting of the ambulacral crest: (0) angle smaller than $45^{\circ}$; (1) angle greater than $45^{\circ}$.

Comments: Tilting of the ambulacral crest and proximal overlapping of the heads are two ways of leading to an overlap of the ambulacrals. Here, the character describes only the tilting of the crest, which is frequent in Asteriidae (Supporting Information, Fig. S5A-G, J, K), but not in the taxa with an enlarged head or without developed crests, such as Pedicellaster hypernotius and Labidiaster annulatus (Supporting Information, Fig. S6E-J). Angles were measured between the ambulacral axis (proximal/distal axis) and the proximal edges of the ambulacral's head (e.g. Supporting Information, Fig. S6R, S).
31. Ambulacral, ambulacral's head: (0) symmetrical; (1) asymmetrical, longer on the proximal side.

Comments: The ambulacral's head can be symmetrical (e.g. Supporting Information, Figs S5A, D, E, H, S, S6A, $\mathrm{K}$ ), or not (e.g. Supporting Information, Figs S5U, X, S6E, H, M, P).

32. Ambulacral, furrow: (0) absent; (1) present, but irregular; (2) present, well-marked.

33. Ambulacral, abactinal surface of the shaft: (0) stereom undifferentiated; (1) glassy trabeculae present.

34. Ambulacral, proximal and distal extension of the ambulacral base (wings) for the muscles dadam and padam: (0) absent; (1) present.

Comments on characters 32, 33, and 34: As for the first ambulacrals (character 10), a furrow can be present on the shaft of the ambulacrals (Fau \& Villier, 2018). The shaft can be composed either of labyrinthic stereom (Supporting Information, Figs S5I, V, S6L, O) or of glassy trabeculae (e.g. Supporting Information, Fig. S5K-N). Wings are absent in Forcipulatacea, except in the Zoroasteridae, Brisingida, Pedicellaster hypernotius and Labidiaster annulatus (Supporting Information, Figs S5S-Y, S6E-L).

35. Ambulacral, articulation area with the superambulacrals (sa): (0) absent; (1) bump present, but undifferentiated stereom; (2) differentiated.

36. Superambulacrals: (0) absent; (1) present, but reduced; (2) present.

Comments for characters 35 and 36: Superambulacrals are present only in the Zoroasteridae and the outgroups (Supporting Information, Fig. S6M, O). These characters are modified from Blake \& Hagdorn (2003: character 39 in character list), Gale (2011: character 69 in character list), and Mah (2007: characters 64 and 65 in character list).

37. Adoral carina: (0) absent; (1) present.

38. Adoral carina: (0) short, one to three adjoining adambulacrals present; (1) long, more than three adambulacrals involved.

39. Adoral carina, teeth on the interradial surface of the adambulacrals of the adoral carina: (0) absent; (1) present.

40. Adoral carina, number of spines on the adambularals of the adoral carina: (0) same number of spines as the other adambulacrals; (1) fewer spines than on other adambulacrals. 
Comments for characters 37 to 40: Adambulacral carina are recognized using the two criteria defined by Fau \& Villier (2018): (1) at least the most proximal adambulacral is in contact with the most proximal adambulacral of the adjacent arm on its adradial side; and (2) presence of a dimorphism between the adambulacrals of the carina and the rest of the adambulacrals (Supporting Information, Fig. S7A, B). Thus, following these criteria, the adoral carina is coded absent in the Brisingida and Pedicellaster hypernotius. Teeth on the adoral carina of Zoroaster fulgens were first described in Fau \& Villier (2018). Teeth occur on the four species of Zoroasteridae studied (Z. fulgens, Z. ophiactis, Z . carinatus philippinensis and Myxoderma sp.; Supporting Information, Fig. S7C, E).

41. Adambulacrals, proximodistal compression of the adambulacral ossicles: (0) not compressed (width = > length); (1) strongly compressed (width $<$ length).

42. Adambulacrals, height: (0) ossicles higher than width; (1) ossicles wider than high.

Comment for characters 41 and 42: Proximodistal compression of the adambulacral ossicles was measured in abactinal view. This character is coded in most phylogenetic studies: character 70 of Gale (2011), characters 6 and 65 of Mah (2000). Adambulacrals are coded as strongly compressed when they are longer than wide (Supporting Information, Fig. S7J-L), adambulacrals that are wider than long (Supporting Information, Fig. S7M, N) were coded as not compressed. Most studied taxa have wider than high adambulacrals (Supporting Information, Fig. S7D-G, I), but three taxa (Heliaster helianthus, Heliaster cumingi and Pisaster ochraceus) have adambulacral that are higher than wide (Supporting Information, Fig. S7H).

43. Adambulacrals, relative size of the muscle insertion dadam and padam: (0) smaller than the muscle insertion padam; (1) approximately the same size as the muscle insertion padam.

44. Adambulacrals, articulation dada: (0) with two distinct surfaces; (1) with confluent surfaces.

Comments for characters 43 and 44: The muscle insertion padam is generally larger than the muscle insertion dadam (Supporting Information, Fig. S7J, K, $\mathrm{M})$, but the two muscle insertions are of rather similar size in a few taxa (Supporting Information, Fig. S7L, N). The articulation dada can be clearly separated into two well-demarcated articulation surfaces (Fig.
S7D, G) or the surfaces can be merged (Supporting Information, Fig. S7F).

45. Adambulacrals, ledge formed by the articulation dada: (0) rather concave; (1) rather flat or convex.

Comments: The two articulations dada form a ledge, especially visible in proximal view, and frame the muscle insertion dadam. This ledge can be flat (Supporting Information, Fig. S7D, E) or concave (Supporting Information, Fig. S7F, G).

46. Adambulacrals, crest between the muscle insertion padam and dadam: (0) absent; (1) present.

Comments: The Zoroasteridae and Brisingida are the only taxa for which the muscle insertions padam et dadam are separated by a small crest (Supporting Information, Figs 7O, T, U, S7N).

47. Adambulacrals, adambulacrals with adaradial extension (carinate adambulacrals): (0) absent; (1) alternatively carinate and non-carinate adambulacrals.

48. Adambulacrals, number of adambulacral spines: (0) constant; (1) variable on adambulacrals of similar size.

Comments: Zoroasteridae are typically described as having alternatively carinate and non-carinate adambulacrals (see adradial extension in Supporting Information, Fig. S7D). However, Fau \& Villier (2018) demonstrated that this character appears relatively late during the ontogeny. It is still an important character to diagnose Zoroasteridae, used in many phylogenetic analyses. We choose to keep this character as only adult specimens are scored in the matrix.

49. Adambulacrals, number of primary spines: (0) 1 to 3 ; (1) 4 and more.

50. Adambulacrals, number of secondary spines: (0) absent; (1) 1 to 3; (2) 4 and more.

51. Adambulacrals, rows of spines oriented lengthwise (furrow spines): (0) absent; (1) present.

Comments for characters 49, 50 and 51: For differences between secondary and primary spines, see comments for character 25. Furrow spines are only present in the outgroups.

52. Adambulacrals, shape of the spines: (0) conical or cylindrical; (1) with a flattened extremity. 
53. Adambulacrals, attachment of the straight pedicellariae: (0) on the adambulacrals; (1) on the spines.

\section{BODY WALL OSSICLES (CHAR. 54-99)}

54. Actinals: (0) absent or reduced, loose in dermal tissues; (1) present.

55. Actinals, number of rows: (0) only a few plates, two or three plates per arm; (1) 1 to 3 rows; (2) 4 and more.

56. Actinals: (0) non-overlapping one to each other; (1) overlapping like roof tiles.

Comments for character 54, 55 and 56: Asteriidae and a few other Forcipulatacea have a reduced number of actinal plate rows, but several rows are usually present in other forcipulataceans (e.g. Stichasteridae, Zoroasteridae). Some Asteriidae (i.e. Notasterias armata, Urasterias linckii, Stephanasterias albula and Coscinasterias tenuispina) do not develop actinal rows at all, only a few actinal plates are present at the disc margins. The actinal cover can be dense, with actinals overlapping each other (Supporting Information, Fig. S8G, I, J), or it can be loose, with only a few actinal plates, set in dermal tissues, and not overlapping (Supporting Information, Fig. S8D).

57. Actinals, primary spines: (0) absent; (1) present.

58. Actinals, number of primary spines: (0) only one spine; (1) 2 or 3 spines; (2) 4 spines and more.

59. Actinals spines: (0) long and slender; (1) short and stout.

Comments for characters 57, 58 and 59: Actinal spines are generally longer than the marginal spines in the Forcipulatacea. Character state (1) short and stout refers only to the shape of the spines found on the actinals, independently of the spines found on other plate types. See comments for character 25 for the definition of primary spines.

60. Actinals: wreath organs: (0) absent; (1) present.

Comments: Wreath organs or rosettes are clusters of crossed pedicellariae arranged around primary spines of asteriids (Lambert et al., 1984; Gale and Villier, 2013). The wreath organs are capable of moving along the spines, in response to stimuli, and are complex structures composed of about 50 crossed pedicellariae and three types of muscles bundles: circular, longitudinal and transverse (Lambert et al., 1984). Wreath organs are coded present or absent only for taxa that have crossed pedicellariae (see character 105), other taxa are coded as non-applicable.

61. Actinals, secondary spines: (0) absent; (1) present.

Comments: Secondary spines are present on actinals only in the Zoroasteridae and the outgroups (see comments for character 25 for the difference between primary and secondary spines).

General comments on marginals: Following previous interpretations (see Discussion), we recognized only one row of marginals in the Zoroasteridae and in the Brisingida.This unique row is considered homologous to the inferomarginal series of the other Forcipulatacean, and is scored accordingly in the matrix.

62. Marginals, number of rows: (0) only one row; (1) two rows.

Comments: For character 62, see the general comments on marginals (above) and Supporting Information, Figure S8.

63. Marginals, intermarginals: (0) absent; (1) present.

Comments: Intermarginals are ossicles inserted between the inferomarginals and the superomarginals (Fig. 9E; Fig. S8D). Intermarginals are present in Asterias forbesi, Asterias rubens and Pisaster ochraceus. In Urasterias linckii, intercalary ossicles are present between the superomarginals. They are not considered homologous with the intermarginals because they do not have the same articulation patterns. Intercalary ossicles are articulated with the superomarginals only, whereas the intermarginals are articulated with both the superomarginals and inferomarginals.

64. Inferomarginals, pitting of the internal face: (0) absent; (1) one pit; (2) two pits.

Comments: Pits can be present on the internal face of the inferomarginals (Supporting Information, Fig. $\mathrm{S} 9 \mathrm{C}, \mathrm{E})$. However, the function of this structure is still unclear. The best assumption is that the pits are muscle insertions that join the inferomarginals and the actinals or the adambulacrals.

65. Inferomarginals, interbrachial wall composed of actinals and inferomarginals: (0) absent; (1) present.

Comments: The arms of Heliaster are fused together at their base. The wall skeleton (i.e. actinals and 
inferomarginals) of the proximal part of the arms form a double interbrachial wall, the so-called discobrachial wall (Clark, 1907).

66. Inferomarginals, number of primary spines: (0) one spine; (1) 2 or 3 spines; (2) 4 spines and more.

67. Inferomarginals, round pustule: (0) absent; (1) present.

68. Inferomarginals, keyhole pustule: (0) absent; (1) present.

69. Inferomarginals, secondary spines attached on bump: (0) absent; (1) present.

Comments for characters 66 to 69: For the definition of primary and secondary spines, see comments for character 25. Pustules can be separated into two categories according to their shape: round pustules and oval pustules called keyhole pustules (Supporting Information, Figs S8, S9). The shape of the pustules seems to depend on spine location. When spines are facing actinally, the pustules are more likely to be keyhole shaped. A keyhole pustule might allow stronger and more oriented spine movement than a round pustule.

70. Inferomarginals, shape: (0) cruciform shape; (1) inverse T shape; (2) block-like.

Comments: In Forcipulatacea, the shape of the actinals, marginals, abactinals and carinals can be described using the lobes formed by the articular facets (Supporting Information, Fig. S9). Most taxa have cruciform shaped ossicles (Supporting Information, Fig. S9F, H, I-L, P). The inferomarginals can be modified, with the actinal lobe reduced, forming an inverse T-shape (Supporting Information, Fig. S9A-E). Thus, inferomarginals are generally either cruciform or inverse T-shaped in Forcipulatacea. The marginals are compressed in several Zoroaster species, due to the reduction of the proximal and distal articular facets (Supporting Information, Figs S8J, S9G). The inferomarginals of Zoroaster were coded as cruciform (Fau \& Villier, 2018). State (2, block-like) describes the marginals of the outgroup Plutonaster bifrons.

71. Inferomarginals, spine tip: (0) conical or circular; (1) flattened.

72. Inferomarginals, spines: (0) similar to the superomarginal spines; (1) thicker and/or longer than the superomarginal spines.

Comments for the characters 71 and 72: Spines can differ in some aspects, especially the inferomarginal spines, which can have a flat tip, or can stand out above the superomarginal spines.
73. Superomarginals, glassy tubercules or microlens arrays: (0) absent; (1) present.

Comments: Glassy tubercles are rare in forcipulatacean asteroids, but they are present on the superomarginals of four studied taxa (Supporting Information, Fig. S9K).

74. Superomarginals, shape: (0) cruciform; falciform; (2) block-like.

Comments: As for inferomarginals, the shape of the superomarginals can be described from their lobe developments. Most of the studied taxa have cruciform superomarginals (Supporting Information, Fig. S9I-L, P). The superomarginals of Neomorphaster forcipatus and Stichaster striatus are falciform, with both proximal and distal lobes reduced (Supporting Information, Fig. S9M-O). State (2, block-like) describes the marginals of the outgroup Plutonaster bifrons.

75. Superomarginals, intercalary ossicles: (0) absent; (1) present.

Comments: See comments for character 63 and Supporting Information, Figure S8D.

76. Superomarginals, shape, size of the abactinal and actinal lobes: (0) abactinal and actinal lobes approximately the same length; (1) actinal lobe longer (abactinal lobe reduced).

Comments: In some taxa, superomarginals, whether they are cruciform or falciform, can have equally developed lobes (Supporting Information, Fig. S9I-J, N-P) or reduced abactinal lobes (Supporting Information, Fig. S9K-M).

77. Superomarginals, number of primary spines: (0) only one spine; (1) 2 or 3 spines; (2) 4 spines and more.

Comments: The most precise way of counting the primary spines is to look for pustules on SEM images (Supporting Information, Fig. S9). Primary spines are constantly attached to pustules, and pustules can be counted even is spines are gone, which is common in collection specimens.

78. Abactinals, number of abactinals separating the carinal from the marginal plate rows: (0) a single series; (1) two series or more.

Comments: The Zoroasteridae (Supporting Information, Fig. S9J), Neomorphaster forcipatus 
(Supporting Information, Fig. S9G), Labidiaster annulatus and Pedicellaster hypernotius have only one row of abactinals. The dissected specimen of Cosmasterias felipes has also only one row of abactinals (MNHN-IE-2013-10675, R = $41 \mathrm{~mm}$ ), but this taxon was coded (1) 'two or more' because it was described as having two rows in large specimens $(\mathrm{R}>50 \mathrm{~mm})$ by Clark \& Downey (1992) and by (Sladen, 1889) as Stichaster felipes $(\mathrm{R}=66 \mathrm{~mm})$. The numbers of abactinal and actinal plates rows are often used in the description of taxa. However, once there is more than one abactinal series, the organization in rows tend to disappear. Two or more rows are visible in some Stichasteridae (e.g. Stichaster striatus; Supporting Information, Fig. S8H), but the organization, and therefore the rows, completely disappear in other taxa when more than one abactinal is present proximally. We, therefore, choose to formulate character 78 by counting the number of abactinals between the carinals and the marginals instead of counting hypothetical rows of abactinals.

79. Abactinals, degree of plate differentiation: $(0)$ plates undifferentiated; (1) at least two level of plates.

Comments: In asteriids, it is possible to differentiate two or more level of abactinals (Fig. S8A-E). Abactinals can be differentiated by looking at three criteria: (1) their relative size, (2) if they bear at least one spine and (3) if they are overlapped by their closest neighbours or if they are overlapping them. Relatively large abactinals that bear spines and overlapping other abactinals are considered as 'principal abactinals' (Supporting Information, Fig. S8; in pink). The rest of the abactinals (Supporting Information, Fig. S8; in light pink) are considered to be 'secondary abactinals'. Secondary abactinals are present only in taxa for which the abactinal skeleton is organized in a mesh (see character 80). Because of the complex organization of the abactinal skeleton in Asteriidae, more than one level of 'secondary abactinals' can be distinguished in some taxa. The differentiation of abactinals is likely to result from the ontogeny, abactinals being added to the network to fill the gaps, creating a mesh, often organized in arc joining the carinals to the marginals (Supporting Information, Fig. S8A, B, D, E).

80. Abactinals, structure of the wall skeleton: (0) compact, with adjoining or overlapping plates; (1) reticulate mesh; (2) reduced.

Comments: Taxa were coded (0) 'compact' when all abactinals are articulated with at least four other plates (i.e. carinals and/or abactinals and/or marginals), (Supporting Information, Fig. S8F-H, J). Rows of abactinal plates are easily recognized only in the case of compact abactinal structure. Taxa were coded (1) 'reticulate mesh' when the abactinals form a reticulate mesh (Supporting Information, Fig. S8A-E, I), with open spaces between the plates and no apparent organization in lateral rows. Taxa were coded as (2) 'reduced' when the abactinal skeleton is reduced to small abactinals in contact with less than two other plates and no abactinals at all could be found on the distal part of the arms (e.g. Pycnopodia helianthoides, Fisher, 1928: pl. 79).

81. Abactinals, intercalary inter-arc ossicles: (0) absent; (1) present.

Comments: The ontogeny of the wall skeleton of forcipulataceans shows that the abactinals are formed diachronically (see Fisher, 1928: pls 44, 53). They are added during growth of each individual, young specimens having less abactinals than older and larger specimens of the same taxon. We assumed this is one of the reasons, if not the principal reason, why a differentiation exists between 'principal abactinals' and 'secondary abactinals' (see comments for character 79). The abactinals tend to be organized in transversal arcs connecting the carinals to the superomarginals during ontogeny (Fisher, 1928: pls 5, 44, 53; Supporting Information, Fig. S8D, E). Theses arcs can be connected together by intercalary 'secondary' abactinals (Supporting Information, Fig. S8).

82. Abactinals, primary spine attached on pustules: (0) absent; (1) present.

Comments: For the difference between secondary and primary spines, see comments for character 25 .

83. Abactinal, spines: wreath organs: (0) absent; (1) present.

Comments: See comments for character 60.

84. Abactinals: (0) flat or slightly arched; (1) strongly arched.

Comments: Abactinals can be rather flat, as with most Asteriidae, or they can be arched, as in most Zoroasteridae and Stichasteridae. Arched abactinals have the actinal and abactinal lobes oriented internally, due to the pressure exerted by the marginals and the carinals.

85. Carinals: (0) absent; (1) present.

86. Carinals, continuity of the ossicle row: (0) continuous; (1) non-continuous.

87. Carinals, row axis: (0) straight; (1) zigzag. 
Comments for characters 86, 87 and 88: Because of the absence of differentiation, no carinals can be recognized in any of the studied Brisingida, or in the outgroup Plutonaster bifrons. The row of carinals can be continuous (Supporting Information, Fig. S8A, B, $\mathrm{D}-\mathrm{H}, \mathrm{J})$ or discontinuous, by addition of intercalary plates between the carinals (Supporting Information, Fig. S8C, I). Generally, rows of carinals are straight, but in some taxa they can form zigzag patterns.

88. Carinals, articular lobes: (0) well-formed; (1) reduced.

89. Carinals, number of articular facets: (0) up to 4 articular facets; (1) more than 4 articular facets.

Comments for characters 89 and 90: Most Forcipulatacea have cruciform carinals, with four lobes bearing four articular facets (Supporting Information, Fig. S8). But in some taxa, lobes can be reduced (Supporting Information, Fig. S8C, H, I), or they can have more than four articular facets (Supporting Information, Fig. S8I, J).

90. Carinals, number of primary spines: (1) 2 or 3 spines; (2) 4 spines and more.

91. Carinals, wreath organ on primary spines: (0) absent; (1) present.

92. Carinals, secondary spines: (0) absent; (1) present.

93. Carinals, glassy tubercles: (0) absent; (1) present.

Comments for characters 91 to 94: Same comments as for characters 25,60 and 73 .

94. Wall skeleton, primary spines (spines on actinals, marginals, abactinals and carinals): (0) long; (1) short.

95. Wall skeleton, primary spines (spines on actinals, marginals, abactinals and carinals): (0) slender; (1) stout.

Comments for characters 95 and 96: Spine morphology varies from one taxon to another. Examples of stout spines are illustrated in Supporting Information, Figure $\mathrm{S} 10 \mathrm{~A}-\mathrm{C}$, and slender spines in Supporting Information, Figure S10D-F. For character 95 , the size of the spines is compared to the size of the specimen.

96. Wall skeleton spines, ornamentation: (0) absent; (1) present.

97. Wall skeleton spines, bifid: (0) absent; (1) present.

Comments for characters 97 and 98: Ornamented spines are present in all Forcipulatacea except in Zoroasteridae and Brisingida (Supporting
Information, Fig. S10A-C). Bifid spines are present only in Brisingaster robillardi and Odinella nutrix (Supporting Information, Fig. S10E).

98. Wall skeleton spines, stereom:(0) undifferentiated stereom; (1) differentiated stereom with glassy trabeculae.

Comments: Spines can be made of undifferentiated stereom, generally labyrinthic stereom (Supporting Information, Fig. S10A-C) or of glassy trabeculae (Supporting Information, Fig. S10D-F).

\section{PEDICELLARIAE (CHAR. 100-111)}

99. Forcipulate pedicellariae: (0) absent; (1) present.

Comments: Forcipulate pedicellariae are three element pedicellariae, articulated with the rest of the body by a muscular peduncle (Chia \& Amerongen, 1975; Lambert et al., 1984; Gale, 2011). There are two types of forcipulate pedicellariae: straight forcipulate pedicellariae and crossed forcipulate pedicellariae (Supporting Information, Fig. S10G-N). Forcipulate pedicellariae are present in all Forcipulatacea, but straight pedicellariae are absent in the Brisingida and crossed pedicellariae are absent in the Zoroasteridae.

100. Straight pedicellariae: (0) absent; (1) present.

101. Straight pedicellariae, felipedal (Clark \& Downey, 1992): (0) absent; (1) present.

102. Straight pedicellariae, valve length relative to the width of the basal piece: (0) short or equal size; (1) 1.5 to 2 times longer.

Comments for characters 101, 102 and 103: Straight forcipulate pedicellariae are absent in Brisingida. Clark \& Downey (1992) recognize two different types of pedicellariae in 'Asteriidae' (which includes the Asteriidae and Stichasteridae presently accepted): lanceolate pedicellariae and felipedal pedicellariae. Both types are generally similar in shape, but felipedal pedicellariae possess one or several teeth that hold together the two valves. The pedicellariae of Pisaster ochraceus are one of the extreme examples of felipedal pedicellariae (Supporting Information, Fig. S10I). Straight pedicellariae can be short (Supporting Information, Fig. S10G) or long (Supporting Information, Fig. S10H), the length of the valve compared to the width of the basal piece was used to express this variation (character 103).

103. Straight pedicellariae, location: (0) present only on the actinal side; (1) present on the whole body. 
Comments: Straight pedicellariae are particularly abundant around the ambulacral furrows and the mouth. In some Forcipulatacea, straight pedicellariae are restricted to these areas, the rest of the body being covered by crossed pedicellariae.

104. Crossed pedicellariae: (0) absent; (1) present.

105. Crossed pedicellariae, rows of distal teeth: (0) up to 3 ; (1) 3 or more.

106. Crossed pedicellariae, differentiated teeth (canines): (0) absent; (1) present.

107. Crossed pedicellariae, shape: (0) common shape; (1) long and slender.

108. Crossed pedicellariae, diastema between the distal teeth and the median teeth: (0) absent; (1) present, curved; (2) present, straight.

109. Crossed pedicellariae, medial projection: (0) absent; (1) present.

Comments: Crossed forcipulate pedicellariae are absent in Zoroasteridae. Crossed pedicellariae can differ in shape, size or by the presence or absence of specific features (Supporting Information, Fig. S10J-N). The description of the crossed pedicellariae follows Chia \& Amerongen (1975). Crossed pedicellariae are composed of a basal piece and two valves, just like the straight pedicellariae. Teeth are present on the valves. Distal teeth can be separate from the median teeth by a diastema. The diastema can be curved into a horseshoe shape (Supporting Information, Fig. S10K), or be straight (Supporting Information, Fig. S10M). The most common type of crossed pedicellariae is the common shape with more than three rows of distal teeth (Supporting Information, Fig. S10J-L). On the contrary, Brisingida has long and slender, crossed pedicellariae, with less than three rows of distal teeth, and with differentiated canines and medial projection bearing median teeth (Supporting Information, Fig. S10M). Some taxa, like Pedicellaster hypernotius, can possess both common-shaped crossed pedicellariae (Supporting Information, Fig. S10J-L) and long and slender crossed pedicellariae (Supporting Information, Fig. S10M, N).
110. Crossed pedicellariae, wreath organ: (0) absent, random distribution of the crossed pedicellariae; (1) present.

Comments: See comments for character 60.

\section{DISC AND TERMINALS (CHAR. 112-116)}

111. Disc, abactinals (all plate except madreporite, radials and interradials): (0) thick, opaque; (1) thin, translucent.

Comments: Only three taxa have weakly mineralized disc plates: Freyella elegans, Odinella nutrix and Labidiaster annulatus. It is interesting to note that these three taxa have a great number of arms, and that their abactinals disappear distally in the arms.

112. Disc, glassy tubercles on radials and interradials: (0) absent; (1) present.

Comments: See comments for character 73 .

113. Madreporite: (0) isolated; (1) embedded in a special cavity of the adjoining interradial; (2) fused with an interradial.

114. Terminal, proximal notch: (0) absent; (1) present.

Comments for characters 113 and 114: All the Asteriidae and Stichasteridae have madreporites fused with an interradial. In the Zoroasteridae, the madreporites are distinct from the interradials but are embedded in a cavity of the adjoining interradial (Fau \& Villier, 2018). This character could not be verified in multi-armed taxa (i.e. Brisingida, Heliaster, Labidiaster annulatus and Pycnopodia helianthoides). Fused and embedded madreporites, as well as proximal notch on terminals are illustrated in Fau \& Villier (2018).

115. Terminal, glassy tubercles: (0) absent; (1) present.

Comments: See comments for character 73. 